\title{
Effects of material properties on structural behavior and safety evaluation of an old arch dam
}

\author{
Anh Kiet Bui*, Pakawat Sancharoen*****, Somnuk Tangtermsirikul****, Ganchai \\ Tanapornraweekit** and Pruettha Nanakorn**** \\ * Faculty of Civil Engineering, Ho Chi Minh City Open University, Ho Chi Minh City, Vietnam \\ ** Construction and Maintenance Technology Research Center (CONTEC), Sirindhorn International Institute of Technology, Thammasat \\ University, Pathum Thani, Thailand \\ **** School of Civil Engineering and Technology, Sirindhorn International Institute of Technology, Thammasat University, Pathum Thani, \\ Thailand \\ *** Corresponding Author: pakawat@siit.tu.ac.th
}

$\begin{array}{ll}\text { Submitted } & : 20 / 02 / 2020 \\ \text { Revised } & : 04 / 08 / 2021 \\ \text { Accepted } & : 15 / 08 / 2021\end{array}$

\begin{abstract}
Safety evaluation is an important task to verify the performance of a dam during its service. For an old dam, the material properties vary from the designed value significantly affecting structural performance. This study investigates the effects of material properties of dam concrete and foundation rock on the structural behavior of an old concrete arch dam during operation. The dam safety is evaluated by using a three-dimensional finite element model (FEM). All main loads, such as water pressure, dam self-weight, and thermal load, are considered in the analysis. An existing 54-year-old concrete arch dam, located in a tropical climate region in Thailand, is employed as a case study. The analysis results show that deformation modulus of the foundation, modulus elasticity of concrete, and the variation of reservoir water level during operation are key factors affecting the dam response. With a deformability modulus of foundation and elasticity modulus of dam concrete, which are about $20 \mathrm{GPa}$ and $44.2 \mathrm{GPa}$, respectively, a good agreement in dam deflections between the analysis and the current monitored data from plumb line equipment can be obtained. It should be noted that the material properties are different from the designed value significantly. Finally, safety evaluation can be properly conducted based on current material properties.
\end{abstract}

Keywords: Arch dam; Thermal analysis; Stress distribution; Dam-foundation interaction; Finite element method (FEM).

\section{INTRODUCTION}

Safety evaluation of existing concrete arch dams during operation is an important task to ensure that the dams are always in good operating condition. Factors (i.e., foundation characteristics, dam concrete properties, seasonal thermal load, sediment pressure, uplift pressure, and variation of reservoir water level) that can cause dam deflections, stresses in the dam body, or even instability of the dam should be considered thoroughly to make rational decisions for maintenance. However, uncertainties of those parameters, such as the actual strength of concrete and deformation 
modulus of foundation, which are also time-dependent, are common issues in the evaluation of the behavior and safety of dams. Therefore, the accuracy of dam safety evaluation can be ensured if those uncertainties are studied.

With a dominant development of simulation based on finite element method, extensive studies in the field of structural analysis of concrete arch dams have been carried out (Altunisik et al., 2018; Campos et al., 2018; Bui et al., 2019; Khaneghahi et al., 2019; Pourbehi \& van Zijl, 2019; Wu et al., 2019). However, the problems, such as thermal effects due to variations of environmental conditions during operation, flexibility of the concrete and rock foundation, and behavior of contraction joints, should be clarified, to enhance the precision of the FEM analysis of arch dams. In the present study, advanced finite element ANSYS program (ANSYS, 2017) is used to investigate the static behavior of a 54-year-old concrete arch dam in Thailand. The main purpose of this study is to consider the effects of various factors, which are temperature load, elastic moduli of the concrete and rock foundation, variation of water levels, and the deflections and stresses of the dam and compare the FEM results with the monitoring data of dam structural behavior. Finally, safety evaluation of dam can be conducted properly based on current material properties.

\section{PARAMETERS AFFECTING DAM STRUCTURAL BEHAVIOUR}

\section{Thermal load}

Due to the complex shape of an arch dam, with varying sections by elevation and arch direction, the temperature load caused by the temperature gradient in the arch dam body should be considered. This gradient is due to water and air temperature, and solar radiation intensity on the dam surfaces. The water temperature plays an important role in affecting the distribution of temperature in the dam body. An analytical formula established by Zhu (1997) has been used to determine the water temperature, which varies with depth and season. In addition, the solar radiation acting on the surface causes a nonuniform distribution of temperature on the dam surface due to the variation of solar radiation intensity and shading effects (Jin et al., 2010; Mirzabozorg et al., 2014; Santillán et al., 2014).

The thermal load caused by a high-temperature gradient may produce tensile stresses on the exposed surface of the dam, which may generate hair cracks on this surface. These cracks do not affect the stability but may cause damage by freezing and thawing due to water penetration into the cracks (Leger et al., 1993; Matsuo et al., 1999). Sheibany and Ghaemian (2006) showed that solar radiation is an important factor for increasing the downstream temperature and contributes to the propagation of cracking in the downstream face of Karaj Dam (an arch dam). In addition, Matsuo et al. (1999) found that the joint opening of an arch dam in Japan caused significant increases of radial deflection due to the volume reduction of concrete in winter when compared to that in summer.

However, in the earlier study relating to the evaluation of thermal load effects on dam behavior, Bui et al. (2019) indicated that the seasonal temperature variation in tropical climate region of Thailand, which causes thermal load on the dam, has a very small effect on the stresses and deflection of the dam.

\section{External Forces}

Water level (WL) change is the main factor affecting the dam behavior (Matsuo et al., 1999; Nishiuchi \& Sakata, 2006; Perner \& Obernhuber, 2010; Wieland \& Kirchen, 2012). In a static structural analysis of the dam, the dam deformations and stresses are considered when the reservoir water level reaches maximum or minimum level during the actual operational condition of the reservoir to evaluate the dam safety (USACE, 1994; Karabulut \& Genis, 2019).

Sediment pressure subject to the dam depends on the sediment's depth. Surveying of the sediment level in the reservoir indicates that the sediment level accumulating at the upstream face of the cantilever block is very low in the 
range of 10-20 m of sediment depth after a period of more than 50 years storage. FERC (1999) described that the sediment depth of less than $25 \%$ of the dam height of U-shape arch dams only caused negligible deformations and stresses, and its effects could be ignored.

Uplift pressure can reduce friction between dam base and foundation. As a result, the safety of the dam can be reduced. However, it can be neglected when the observation at the dam site indicated that no leakage occurs downstream. In addition, uplift pressure only causes a minor change in stresses, and its effects do not need to be considered in the stress analysis for thin arch dams (FERC, 1999).

Seismic load is an important factor and needs to be considered for the overall dam safety evaluation. Effects of joint opening during earthquake (Fenves et al., 1992; Zhang et al., 2000; Zhou et al., 2000; Hariri-Ardebili et al., 2013; Hariri-Ardebili \& Kianoush, 2015; Zhang et al., 2019; Zhang et al., 2019), effects of hydrodynamic and water compressibility (Fok \& Chopra, 1987; Wang et al., 2012; Hariri-Ardebili \& Kianoush, 2014), dam-water-foundation interaction (Tan \& Chopra, 1995; Wang et al., 2013; Hariri-Ardebili \& Kianoush, 2015; Varughese \& Nikithan, 2016; Pourbehi \& van Zijl, 2019; Zhang et al., 2019), effects of spatially varying ground motion (Chopra \& Wang, 2010; Wang \& Chopra, 2010; Ghaemian \& Sohrabi-Gilani, 2012; Mirzabozorg et al., 2013), effects of foundation inhomogeneity (Lin et al., 2007), etc. are problems that have been investigated recently. Some past studies indicated that seismic load could cause propagation of cracks on the upper half parts of arch dams if the intensity of earthquake was high enough (Zhong et al., 2009; Hariri-Ardebili \& Kianoush, 2014). However, since the analysis in this paper relates to the behavior of the dam in the static stage, this load is out of scope and is not considered in the present study.

\section{Material Properties}

To precisely evaluate the static behavior of an arch dam during operation, the effects of uncertainties of material properties should be investigated (Khaneghahi et al., 2019). Proper foundation characteristics need to be determined based on type of foundation rock and discontinuities presenting in the foundation. It is acceptable to assume that the modulus of deformation of rock mass with high quality is a uniform average modulus for the entire foundation. The stiffness of the foundation rock is the crucial factor affecting the real behavior of the concrete arch dam (Colombo et al., 2016). Geomechanical parameters of the foundation rock produced significant impact on the long-term service safety of high arch dams (Wu et al., 2019). In other aspect, the response of the arch dam is affected by the deformation modulus of foundation to the elastic modulus of concrete ratio $\left(E_{f} / E_{c}\right)$. FERC (1999) indicated that hydrostatic deflections are more sensitive to soft foundation $\operatorname{rock}\left(E_{f} / E_{c}<1\right)$ and increase significantly in case of $E_{f} / E_{c}$ lower than 0.5 . In contrast, the dam deflections for a stiff foundation rock $\left(E_{f} / E_{c}>1\right)$ change only slightly when compared to those for a rigid foundation.

Concrete properties also change with time. Mainly, cement hydration process continues for the long term or even slowly increases at the later age. Also, a creep of concrete causes volume reduction and affects the dam behavior. However, a creep of concrete is significant only in the initial period of the dam (less than 10 years).

\section{METHODOLOGY}

\section{Dam Description}

The 54-year-old arch dam, located at $17^{0} 14.55^{\prime}$ latitude and $98^{0} 58.33^{\prime}$ longitude on the Ping River in Tak province, Thailand, was selected as a case study. The dam is considered a moderately thin arch dam (USACE, 1994) that was formed by 25 vertical blocks. The maximum dam height is $150 \mathrm{~m}$ from the foundation rock with its crest elevation at $261 \mathrm{~m}$ amsl. The arch length at crest elevation is $475 \mathrm{~m}$ with an arch radius of $250 \mathrm{~m}$. The dam thickness 
at the crest and bottom of the cantilever block is $6 \mathrm{~m}$ and $44 \mathrm{~m}$, respectively. The designed maximum operational water level is at $260 \mathrm{~m}$ amsl with a full storage capacity of $13.5 \times 10^{9} \mathrm{~m}^{3}$ and the minimum level at $213 \mathrm{~m}$ amsl. The dam was built for multipurposes as to generate electricity, control flooding, improve navigation, and store water for irrigation. Figure 1 shows details, obtained from actual drawing, of the dimensions of the dam in plain view and crown section of cantilever block.

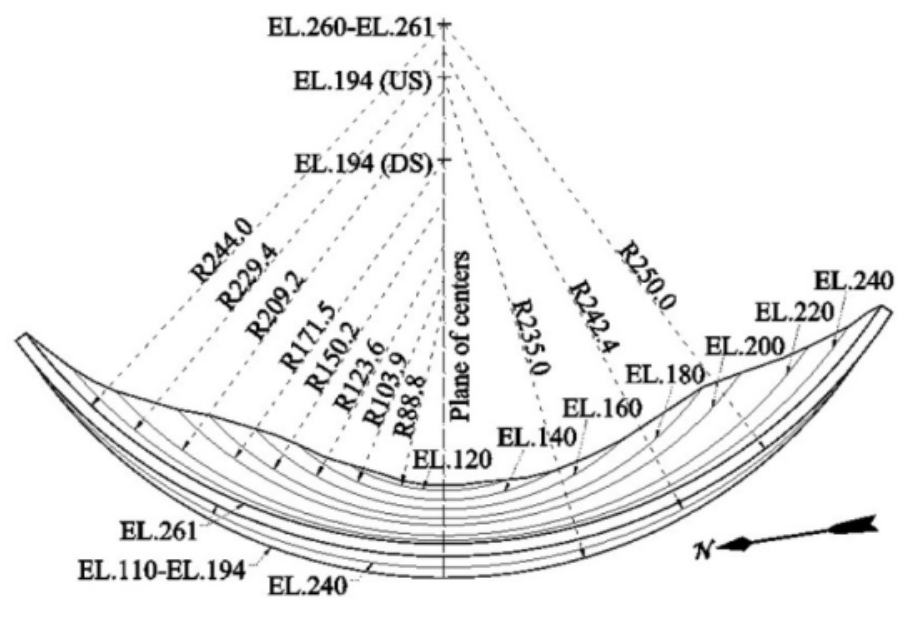

(a)

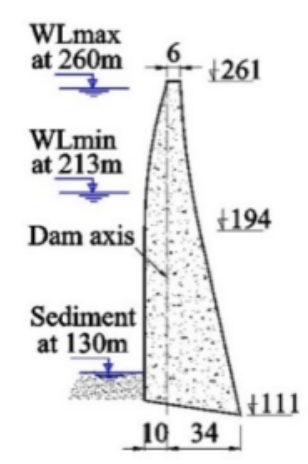

(b)

Figure 1. Basic dimensions of the dam: (a) plain view and (b) crown section of cantilever block.

\section{Uncertainties of Material Properties}

\section{Foundation}

Information about geology collected from Bureau of Reclamation (1955) shows that the geological condition at the dam site lies in a wide band of extremely hard rock (lime silicate hornfels), which strikes across the river. Joints could be seen on the rock surface, but no open joints were found in the core samples. As the dam was constructed for more than 50 years, the material parameters, e.g., modulus of elasticity, compressive strength, and tensile strength, were determined through intact rock samples. No information of deformation modulus of rock mass of the foundation can be obtained from the technical reports of the dam's foundation. So, the values of these parameters, which were used in the FEM model, were determined based on rock mass classification systems, such as Geological Strength Index (GSI) (Hoek \& Brown, 1997).

Deformation modulus can be measured directly by borehole stress method, but the cost is relative high. So, GSI index is used to evaluate the value of deformation modulus in this study. The cored samples of the foundation rock at the dam site showed that the rock type is Lime-Silicate hornfels. Based on the surface conditions (Rough, slightly weathered) and structure of the rock (interlocked, partially disturbed rock mass with multifaceted angular blocks formed by discontinuity sets), the GSI index is determined with a value of 70 (Hoek \& Brown, 1997). Then, the deformation modulus can be calculated by the Simplified Hoek and Diederichs equation (Hoek \& Diederichs, 2006) as shown in Equation (1).

$$
E_{r m}(\mathrm{MPa})=100000\left(\frac{1-D / 2}{1+e^{((75+25 D-G S I) / 11)}}\right)
$$


where $\mathrm{D}$ is the disturbance factor, and $\mathrm{D}$ varies from 0 (undisturbed) to 1 (fully disturbed).

The deformation moduli of the rock mass, calculated from Equation (1) with the disturbance factor varying from 0 to 1 , are in the range of 3.07-38.83 GPa as shown in Table 1 .

Table 1. Deformation modulus of rock mass (GPa) based on standards.

\begin{tabular}{|c|c|c|c|}
\hline Parameter & Unit & Design value & GSI \\
\hline Deformation modulus & $\mathrm{GPa}$ & $34.5^{*}$ & $3.07-38.83$ \\
\hline \multicolumn{2}{|c|}{${ }^{*}$ The value is mentioned in the report (Royal Irrigation Department, 1963). } \\
\hline
\end{tabular}

In this study, the deformation modulus of the foundation rock is assumed to be uniform for the entire of the foundation domain in the model. As can be seen, a large variation of deformation modulus of rock mass when considering different classification systems can be observed. Three cases of foundation deformability of rock mass, which are 10, 20, and $34.5 \mathrm{GPa}$ (covering the range in Table 1), are used in the analysis. The effects of foundation deformability together with water levels and thermal load on the behavior of the dam-water-foundation system are considered. It should be noted that the designed value of foundation modulus was 34.5GPA.

\section{Concrete}

Modulus of elasticity of the dam concrete is an important factor to evaluate the dam behavior, but it is difficult to obtain the representative value since the dam size is large, and samples must be very big and cannot be taken at many locations. The calculated modulus of elasticity from the tested result of compressive strength at 1-year of the specimens taken during the construction (Bureau of Reclamation, 1963) by applying Equation (2) (ACI 318-19, 2019) is $33.3 \mathrm{GPa}$ as shown in Table 2. However, the modulus was found to increase with time. The average value of modulus of elasticity, obtained from the test of cored concrete samples taken in 2010 from the upstream face of the dam at the age of the dam concrete of 48 years, is $44.2 \mathrm{GPa}$. So, both values were used in the analysis in this study. Table 2 summarizes the modulus of elasticity of concrete obtained at different ages. It can be seen that the concrete modulus increased about $33 \%$ in almost 50 years.

$E_{c}=0.043 w_{c}^{1.5} \sqrt{f_{c}^{\prime}}(\mathrm{MPa})$

where $w_{c}$ and $f_{c}^{\prime}$ are the density and compressive strength of concrete, respectively.

Table 2. Modulus of elasticity of dam concrete obtained from different methods.

\begin{tabular}{|c|c|c|c|}
\hline Parameter & Unit & 1-year specimens & Cored specimens \\
\hline Modulus of elasticity & $\mathrm{GPa}$ & 33.3 & 44.2 \\
\hline
\end{tabular}


To evaluate the effects of modulus of elasticity of dam concrete and deformation modulus of foundation rock on the dam behavior, a parametric study is conducted by varying cases of combinations of the aforementioned properties of concrete and foundation in the analysis as shown in Table 3.

Due to a shortage of information of tensile strength of the dam concrete, the tensile strength of the dam concrete was estimated using Raphael's equation (Raphael 1984) as proposed in FERC (1999). The calculated tensile strength was found in the range of $9 \%-12 \%$ of compression strength. Therefore, the tensile strength of about $10 \%$ of the compressive strength was used for the conservative evaluation of the dam safety in this study.

Table 3. Parameters of concrete and foundation used in analysis of cases.

\begin{tabular}{|c|c|c|c|c|c|c|c|}
\hline \multirow{3}{*}{ Parameter } & \multirow{3}{*}{ Unit } & \multicolumn{6}{|c|}{ Case } \\
\hline & & \multicolumn{3}{|c|}{ 1-year age } & \multicolumn{3}{|c|}{ 48-year age } \\
\hline & & 1 & 2 & 3 & 4 & 5 & 6 \\
\hline \multicolumn{8}{|c|}{ CONCRETE } \\
\hline Modulus of elasticity $\left(E_{c}\right)$ & GPa & 33.3 & 33.3 & 33.3 & 44.2 & 44.2 & 44.2 \\
\hline Density $\left(\rho_{c}\right)$ & $\mathrm{kg} / \mathrm{m}^{3}$ & 2480 & 2480 & 2480 & 2480 & 2480 & 2480 \\
\hline Poison's ratio & --- & 0.26 & 0.26 & 0.26 & 0.23 & 0.23 & 0.23 \\
\hline Compressive strength $f_{c}^{\prime}$ & $\mathrm{MPa}$ & 39.34 & 39.34 & 39.34 & 51.29 & 51.29 & 51.29 \\
\hline Tensile strength $f_{t}$ (a) & $\mathrm{MPa}$ & 3.93 & 3.93 & 3.93 & 5.13 & 5.13 & 5.13 \\
\hline \multicolumn{8}{|c|}{ FOUNDATION } \\
\hline Deformation modulus $\left(E_{f}\right)$ & $\mathrm{GPa}$ & 10 & 20 & 34.5 & 10 & 20 & 34.5 \\
\hline Density $\left(\rho_{f}\right)^{(\mathrm{b})}$ & $\mathrm{kg} / \mathrm{m}^{3}$ & 2860 & 2860 & 2860 & 2860 & 2860 & 2860 \\
\hline Poison's ratio ${ }^{(b)}$ & --- & 0.16 & 0.16 & 0.16 & 0.16 & 0.16 & 0.16 \\
\hline
\end{tabular}

\section{Loads}

\section{Gravity Loads}

Gravity loads caused by weight of dam concrete and foundation are considered in the model and computed from the density and geometry of the dam and foundation in the FEM model.

\section{Thermal Load}


Thermal load due to the variation of environmental conditions during the operation period, affecting the dam, is a complicated behavior. A transient thermal analysis is conducted to simulate the temperature distribution in the dam body. All major factors, such as variation of reservoir water temperature at different water depths, hourly air temperature, and hourly average global solar radiation, were taken into account in the thermal analysis of the dam. Figure 2 illustrates the thermal transfer mechanism used for the transient thermal analysis of the present dam.

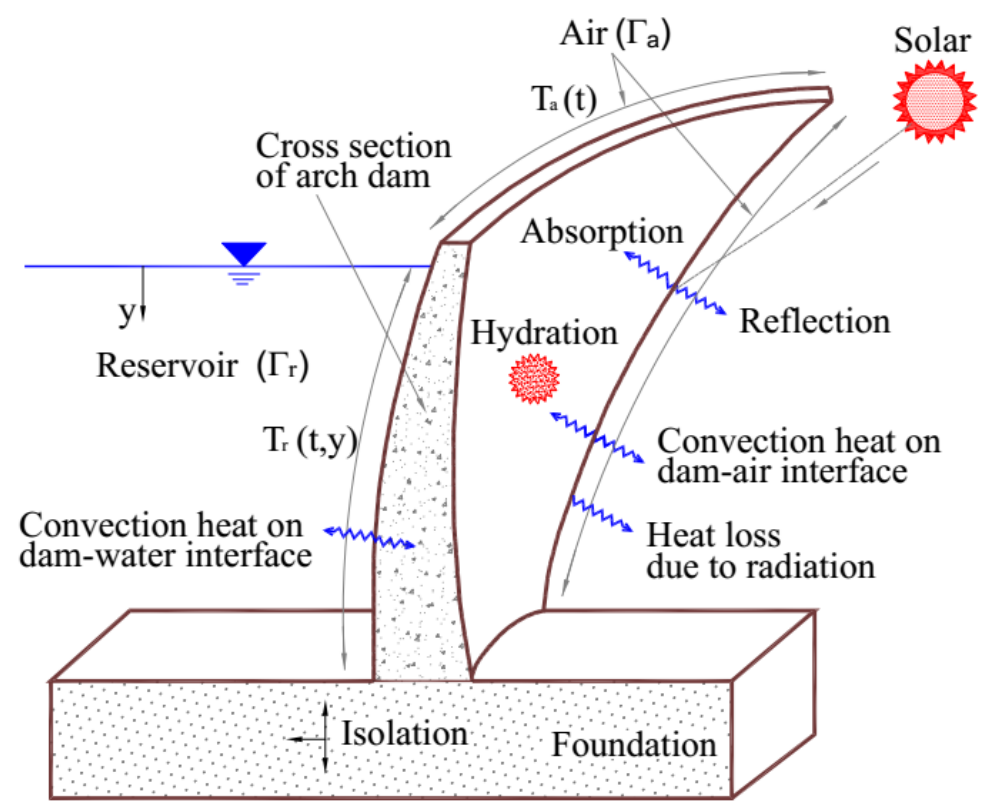

Figure 2. Heat transfer mechanism of the arch dam.

The thermal conduction equation for an arch dam with the dam concrete having uniform and isotropic thermal properties expressed in the Cartesian coordinate system is shown in Equation (3) (Holman, 2010).

$k\left(\frac{\partial^{2} T}{\partial x^{2}}+\frac{\partial^{2} T}{\partial y^{2}}+\frac{\partial^{2} T}{\partial z^{2}}\right)+Q=\rho C \frac{\partial T}{\partial t}$

where $k, \rho, C$, and $Q$ are thermal conductivity $\left(\mathrm{W} / \mathrm{m}^{\circ} \mathrm{C}\right)$, density $\left(\mathrm{kg} / \mathrm{m}^{3}\right)$, specific heat $\left(\mathrm{J} / \mathrm{kg}^{\circ} \mathrm{C}\right)$, and internal heat generated per unit volume $\left(\mathrm{W} / \mathrm{m}^{3}\right)$ of concrete, respectively; $T$ is temperature of concrete $\left({ }^{\circ} \mathrm{C}\right)$, and $t$ is time $(\mathrm{s})$.

It is noted that the internal heat generation $Q$ from cement hydration process had been completed long ago because the age of the dam is more than 54 years. So, the effects of heat generation $Q$ causing the temperature change in the dam concrete due to hydration heat can be ignored.

The boundary conditions are used to solve Equation (3) as given in Equations (4) and (5) (Bui et al., 2019).

$k\left(\frac{\partial T}{\partial x} n_{x}+\frac{\partial T}{\partial y} n_{y}+\frac{\partial T}{\partial z} n_{z}\right)=q_{a}+q_{c-a}+q_{r}$

$k\left(\frac{\partial T}{\partial x} n_{x}+\frac{\partial T}{\partial y} n_{y}+\frac{\partial T}{\partial z} n_{z}\right)=q_{c-w}$ 
where $q_{a}, q_{c-a}, q_{c-w}$, and $q_{r}$ are heat fluxes $\left(\mathrm{W} / \mathrm{m}^{2}\right)$ due to absorption from solar radiation, convection on concrete-air interface, convection on concrete-water surface, and radiation, respectively.

The thermal properties of the dam concrete used in the transient thermal analysis are presented in Table 4.

Table 4. Thermal and other properties used in the analysis (Bui et al., 2019).

\begin{tabular}{|c|c|c|c|}
\hline Parameter & Symbol & Unit & Value \\
\hline Thermal conductivity & $k$ & $\mathrm{~W} / \mathrm{m}^{\circ} \mathrm{C}$ & 2.72 \\
\hline Specific heat & $C$ & $\mathrm{~J} / \mathrm{kg}^{\circ} \mathrm{C}$ & 983 \\
\hline Dam-air convection coefficient & $h_{c-a}$ & $\mathrm{~W} / \mathrm{m}^{2}{ }^{\circ} \mathrm{C}$ & 14 \\
\hline Dam-water convection coefficient & $h_{c-w}$ & $\mathrm{~W} / \mathrm{m}^{2}{ }^{\circ} \mathrm{C}$ & 340 \\
\hline Emissivity coefficient & $e$ & - & 0.88 \\
\hline Solar absorptivity coefficient & $\delta$ & - & 0.60 \\
\hline
\end{tabular}

The reservoir water temperature assigned at the concrete-water interface is calculated by modified Zhu's analytical equation as shown in Equation (6) (Bui et al., 2019).

Due to tropical climate in Thailand, the reservoir water temperature is different from cold climate countries. As a result, reservoir water temperature at the concrete-water interface is calculated by modified Zhu's analytical equation as shown in Equation (6).

$T(y, t)=T_{m}(y)+A_{y} \cos \omega\left(t-t_{0}-\varepsilon\right)$

where $T(y, t), T_{m}(y)$, and $A_{y}$ are the temperature $\left({ }^{\circ} \mathrm{C}\right)$ versus time $t$ (day) at depth $y(\mathrm{~m})$, mean annual temperature $\left({ }^{\circ} \mathrm{C}\right)$, and amplitude of annual temperature variations $\left({ }^{\circ} \mathrm{C}\right)$ of the reservoir water, respectively, $\omega$ is the frequency of temperature variations, and $t_{0}$ and $\varepsilon$ are the time (day) at maximum air temperature and the phase difference (day) between the maximum temperature of water and air, respectively.

The calculated water temperature of the reservoir in 2013 is shown in Figure 3 as an example. As can be seen, large fluctuations of water temperature mainly occur in the upper part of the reservoir (from the free water surface to a depth of $15 \mathrm{~m}$ below the free surface), while the temperature of the lower part below a depth of $50 \mathrm{~m}$ is almost unchanged. It is noted here that daily or monthly fluctuation of air temperature in tropical regions is different from that in cold country regions. 


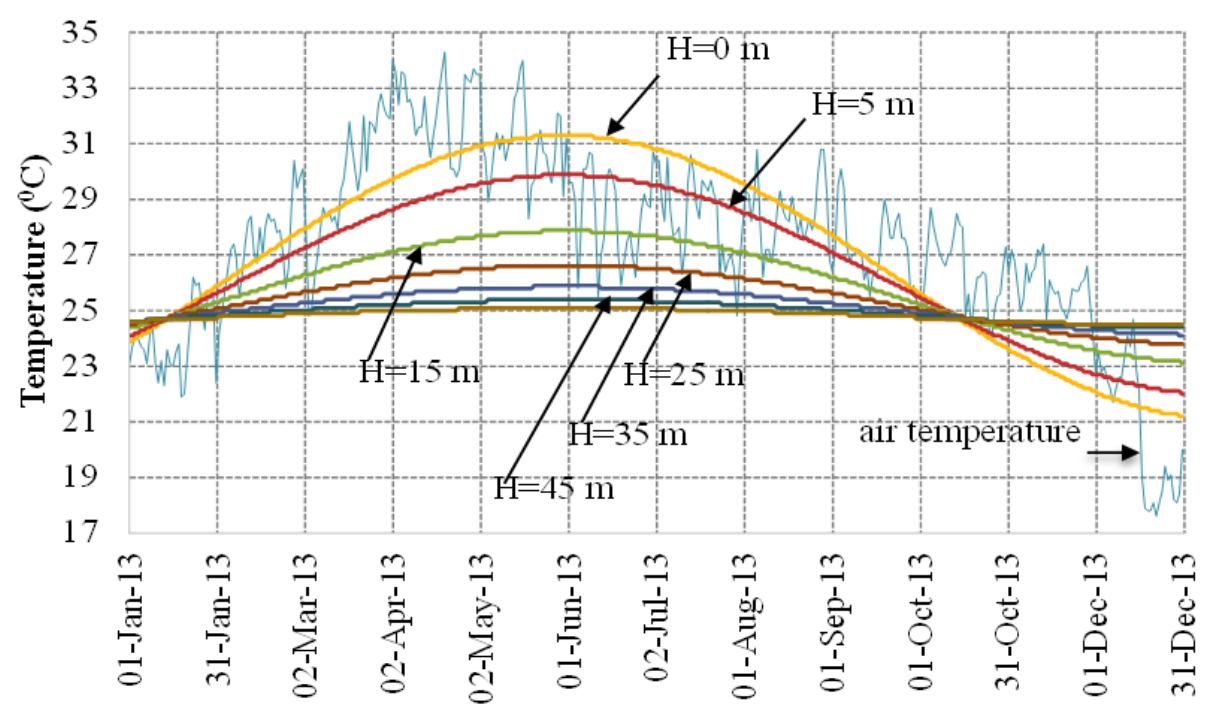

Figure 3. Calculated water temperature in 2013.

Figure 4 shows the comparison between the reservoir water temperature by depths, calculated from Equation (6), used for the input data of the model and the average monitored water temperature of the reservoir measured at different depths in Mar 2018. It can be seen that the differences between water temperature estimated by Equation (6) and the monitored data only differ in a small range of less than $2{ }^{\circ} \mathrm{C}$ at the water surface, and they are well-fit at lower parts of the reservoir (more than $30 \mathrm{~m}$ depth). Thus, the calculated water temperature in tropical climate of Thailand by modified Zhu's equation gives a good agreement with observed data conducted by the authors.

\section{Water temperature $\left({ }^{0} \mathrm{C}\right)$}

$\begin{array}{llllllllll}24.5 & 25.0 & 25.5 & 26.0 & 26.5 & 27.0 & 27.5 & 28.0 & 28.5 & 29.0\end{array}$

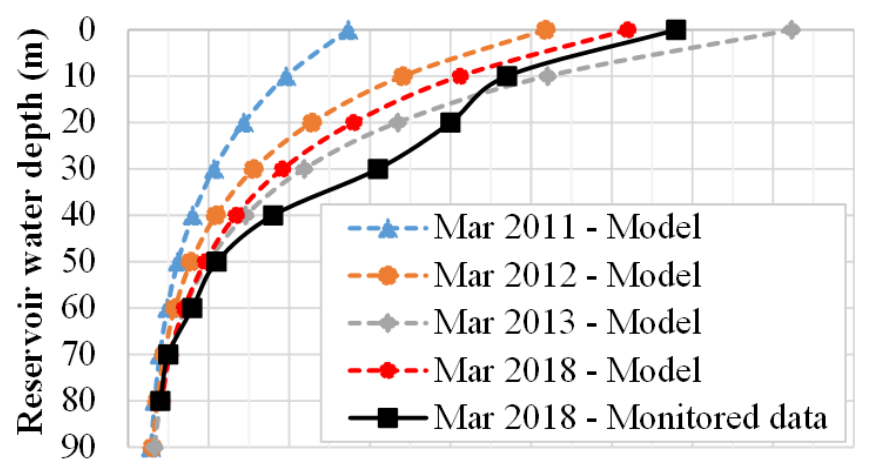

Figure 4. Comparison of reservoir water temperature used in the analysis and monitored data $\left({ }^{\circ} \mathrm{C}\right)$.

In addition, the actual data of hourly air temperature (Figure 5) and hourly average global radiation (Figure 6) at the dam site were collected from the Thai Meteorological Department (TMD). According to the orientation of the dam, which is in a North-South direction, the effects of solar radiation on dam faces can be divided into three parts, which are downstream face, crest, and upstream face above the reservoir water level. 


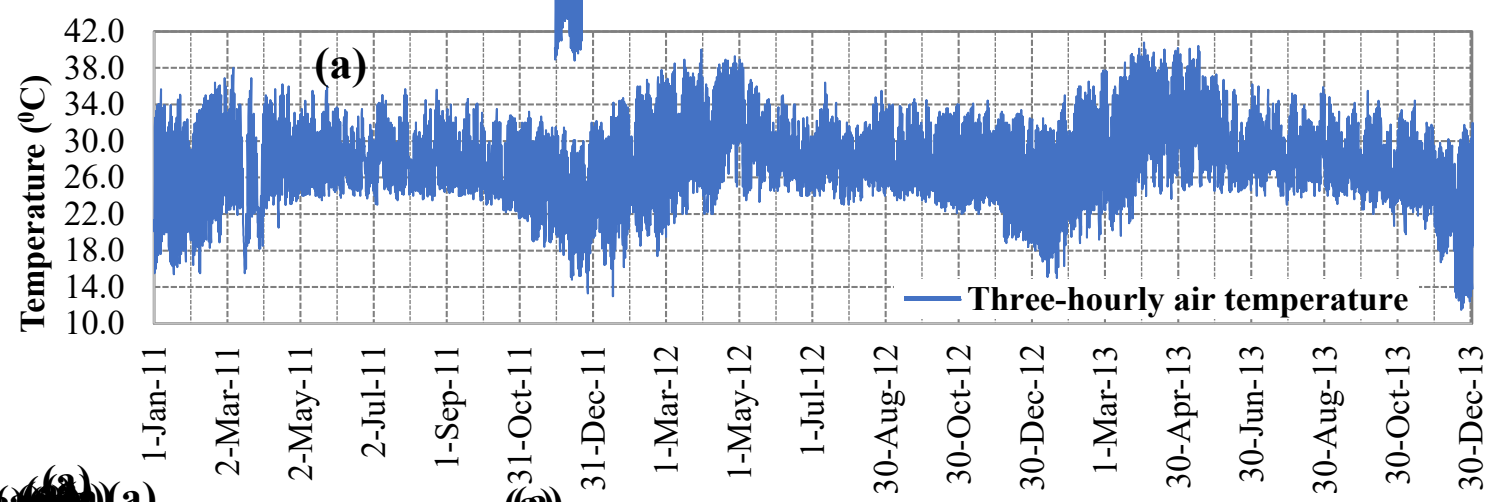

Figure 5. Three-hourly air temperature history at Tak station near the dam during 2011-2013.

(a)

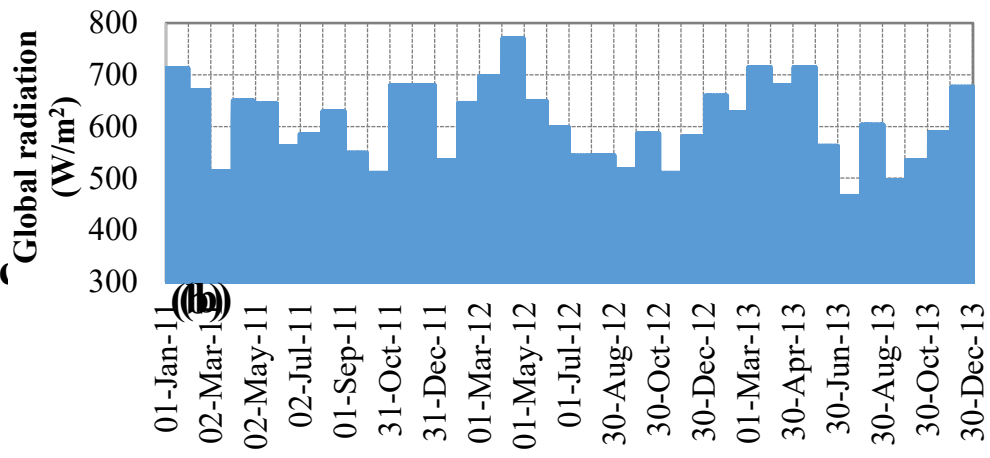

(b)

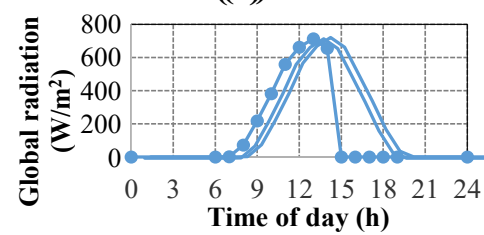

Downstream face

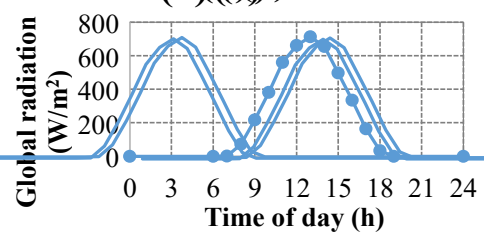

Crest face

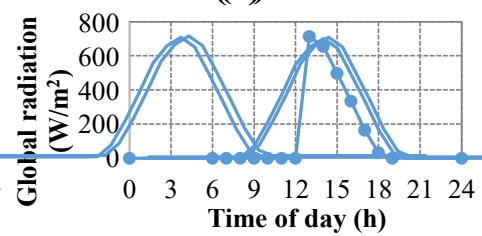

Upstream face above free water surface

Figure 6. Solar radiation during 2011-2013:

(a) solar intensity and (b) typical daily heat flux affecting on dam faces.

\section{Water Pressure}

Instead of applying hydrostatic pressure that was normally used for straight dams, the Lagrangian approach is used to model the reservoir water domain by using modified elastic elements. The benefit of using the water domain is to support for dynamic analysis. The properties for the nearly incompressible material of these elements, including a density of $10 \mathrm{kN} / \mathrm{m}^{3}$, a bulk modulus of $2131 \mathrm{MPa}$, and a Poisson's ratio of 0.495 , are applied for the water domain of the reservoir (Ferdousi et al., 2014). 
In the study, the reservoir water level, which varies from the maximum of $260 \mathrm{~m}$ amsl to the minimum of 215.4 $\mathrm{m}$ amsl during the operation phase, is used to evaluate the dam safety. It is noted here that the water level at minimum of $215.4 \mathrm{~m}$ amsl is used as the reference water level, and deflection of the dam measured by plumb line is initialized. In this study, water levels of $260 \mathrm{~m}$ and $220 \mathrm{~m}$ amsl are used to present the results of stresses and deflections at high and low water levels, respectively, of the dam.

\section{Sediment Pressure, Uplift Pressure}

Due to the small effects of sediment pressure and uplift pressure on the dam stress as mentioned in subsection 2.2 , these loads are not considered in the study.

\section{Finite Element Model}

\section{Selection of the Size of the Model}

The deformability of the foundation rock of an arch dam can affect the behavior of the whole structure (Raychowdhury \& Jindal, 2014). The size of the foundation rock in the model is determined based on the ratio of the foundation deformation modulus to the concrete modulus of elasticity $\left(E_{f} / E_{c}\right)$ (FERC, 1999). The model size should be larger for a smaller ratio of $E_{f} / E_{c}$.

Based on the minimum ratio of $E_{f} / E_{c}$ determined from Table 3, of which its value is equal to 0.23 , the size of the model should be approximately 1.5 to 2.0 times the dam height (H) (FERC, 1999). A parametric study of the $E_{f} / E_{c}$ ratio, varying in the range of 1.0-1.75 times of the dam height, was conducted. The results of the radial deflection at the crown section of the dam at water level of $260 \mathrm{~m}$ amsl corresponding to the extended sizes of the foundation are shown in Figure 7.

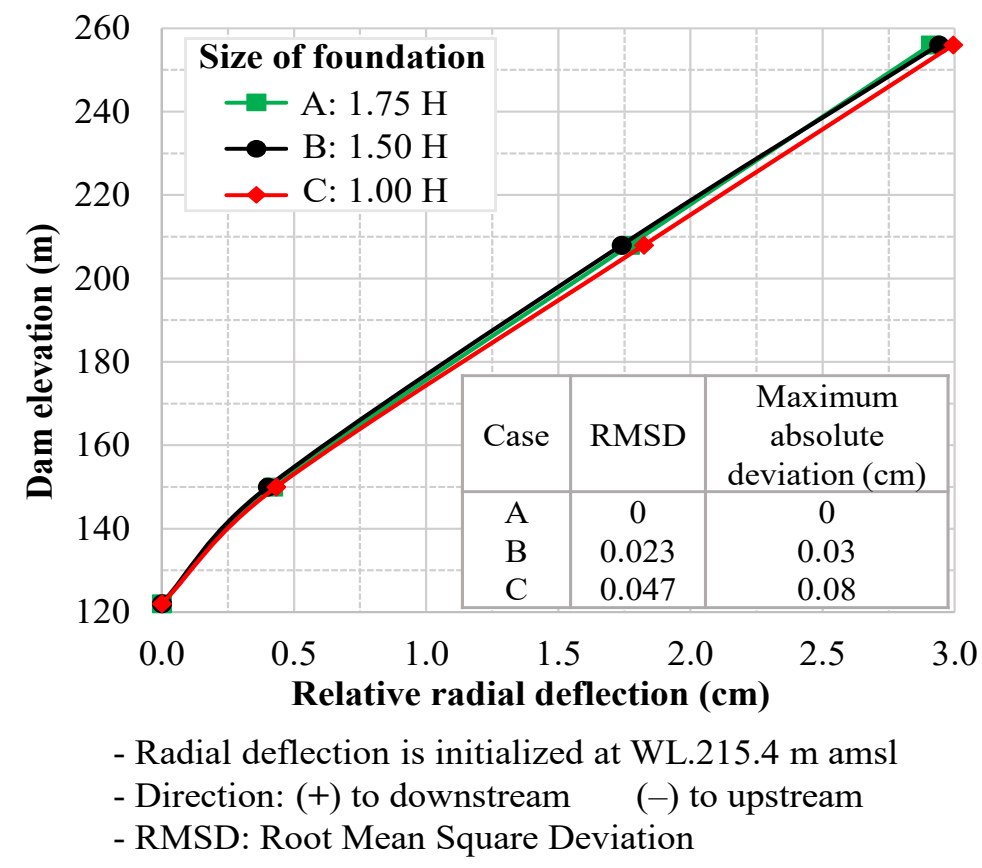

Figure 7. Comparison of radial deflection at the crown section with different sizes of the foundation. 
The results indicate that sizes of foundation in the range of 1.5 and 1.75 times of dam height give almost exactly the same radial deflection results, while clear differences can be seen when the size of foundation is 1.0 time the dam height. So, a foundation size of 1.5 times the dam height is selected for the 3D-FE model in this study.

The water reservoir domain is normally modelled in the range of 2-5 times the dam height in the upstream direction (Ghaemian \& Sohrabi-Gilani, 2012; Wang et al., 2012; Hariri-Ardebili \& Kianoush, 2015). For supporting the dynamic analyses in future study, the reservoir is recommended to extend to about 3 times the dam height in upstream direction. In addition, to enhance the similarity of the model to the actual condition of the dam, the actual terrain of the valley near the dam area based on original rock excavation drawings and reservoir topographic maps is considered in the FE model.

\section{Meshing and Boundary Conditions}

The 3D dam-foundation-water system is created by using advanced finite element ANSYS program (ANSYS, 2017). A convergent analysis was conducted to determine the sufficient fineness of the FE mesh. As a result, a number of 71,493 solid elements (SOLID186) with 268,262 nodes are used in the model, in which the numbers of 8800 and 46851 elements correspond to dam concrete and foundation rock, while the other 15762 are defined as modified elastic elements and assigned for the water domain.

The fixed-boundary conditions are applied to all nodes located in the boundary faces of the foundation. In addition, nodes at the far-end boundary of water domain, where they neither contact with the dam nor with the foundation, are only constrained in the stream direction ( $\mathrm{Y}$ direction) but free in the others ( $\mathrm{X}$ and $\mathrm{Z}$ directions) as shown in Figure 8.

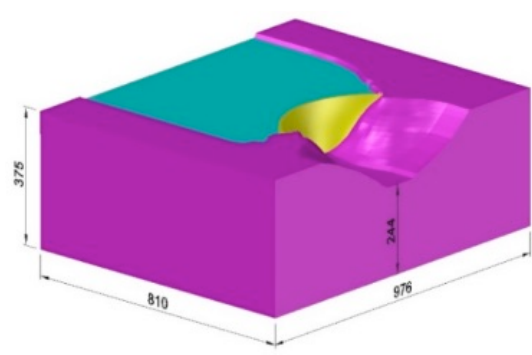

(a)

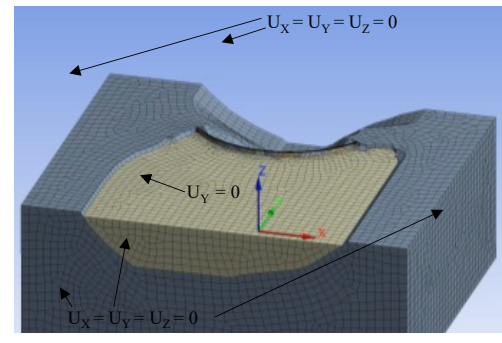

(b)

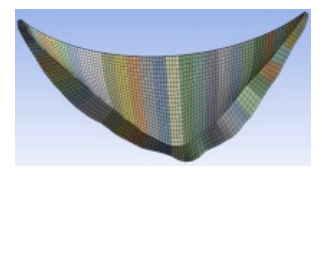

(c)

Figure 8. Finite element model of Dam-Foundation-Water system:

(a) dimension of the model, (b) boundary conditions, and (c) arch dam meshing.

\section{Modelling of Contraction Joints}

To model the behavior of the vertical contraction joints and the contact of dam-foundation rock, the elements named CONTACT174 and TARGET 170, available in ANSYS (ANSYS, 2017), are used. Based on the monitoring data of 3D-joint meters installed at contraction joints in the dam body, all joints have closed (without any gaps between joints) during the operational period. Consequently, it can be assumed that all contacts can transfer the force perfectly. Also, Bonded Contact, an option used for the simulation of perfect contact behavior available in the 
software, is used in this model for the definition of contraction joints between adjacent concrete blocks and also interfaces of dam concrete and foundation rock.

\section{RESULTS AND DISCUSSION}

\section{Effects of Thermal Load}

Figure 9 shows an example of the temperature distribution in the dam body on typical days of the hottest month (April) and coldest month (December) in Thailand. It can be clearly seen that the downstream face is strongly affected by air temperature and solar radiation (larger variation), while the upstream face submerged in the reservoir water is mainly affected by water temperature (smaller variation).

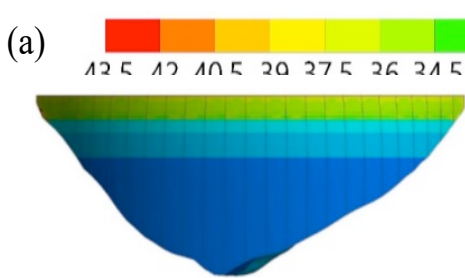

(a1)

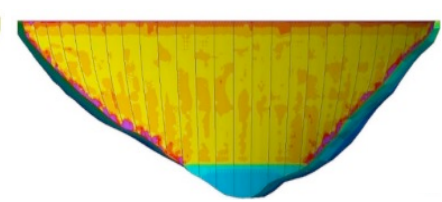

(a2)

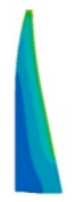

(a3)

\section{$\left({ }^{0} \mathrm{C}\right)$}

(b)

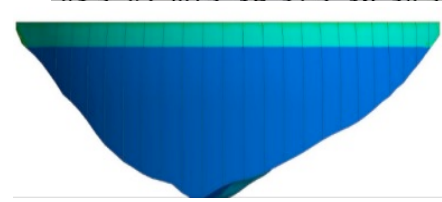

(b1)

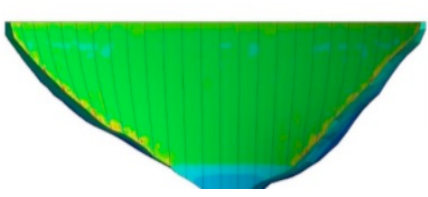

(b2)

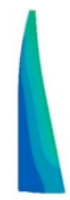

(b3)

Figure 9. An example of temperature distribution in the dam body $\left({ }^{0} \mathrm{C}\right)$ at $2 \mathrm{pm}$ on (a) midmonth of April: (a1) upstream face; (a2) downstream face; (a3) section, and (b) midmonth of December: (b1) upstream face; (b2) downstream face; (b3) section.

To validate the thermal analysis results, Infrared Camera was used to measure the concrete surface temperature at the dam site. The measured temperature differences between concrete dam surface and air temperature observed from field measurement are shown in Figure 10. This data from field measurement gives a good agreement with FEM analysis results in which the solar radiation causes up to $6{ }^{\circ} \mathrm{C}$ increase of temperature on the dam surfaces and causes the nonuniform distribution near the dam surface. 


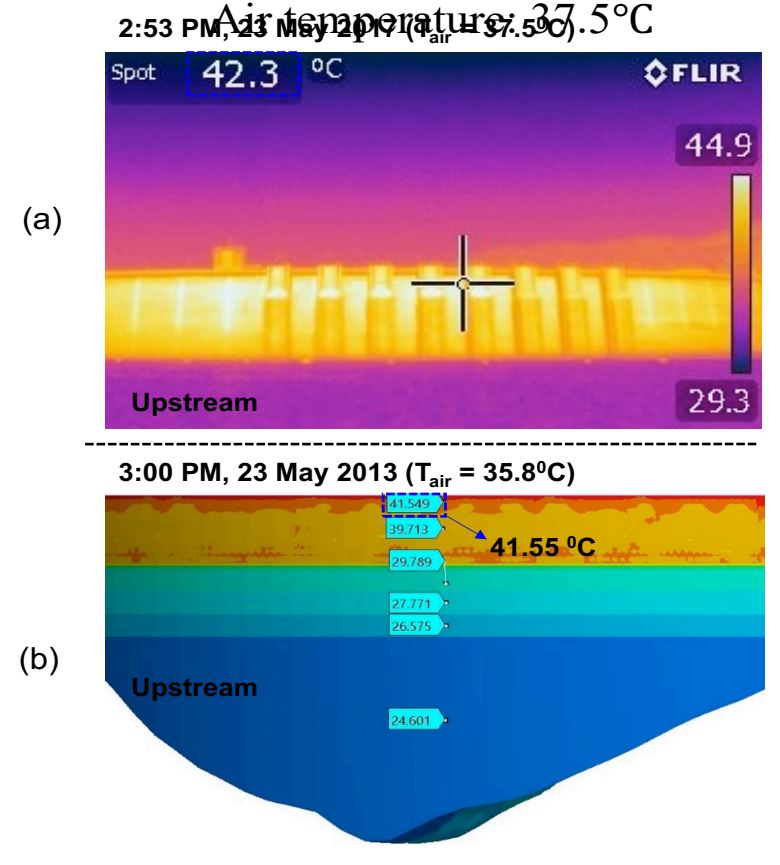

$\begin{array}{lllllllllllllll}43.5 & 42 & 40.5 & 39 & 37.5 & 36 & 34.5 & 33 & 31.5 & 30 & 28.5 & 27 & 25.5 & 24 & 22.5\end{array}$

Figure 10. Comparison of dam surface temperature between

(a) field measurement observed by Infrared Camera and (b) analysis result.

The temperature distribution in the dam body from the thermal analysis results is then used as the thermal load for a linear structural analysis to evaluate the temperature effects. Figure 11 shows the stress distribution caused only by the thermal load for two cases, corresponding to a day in summer and a day in winter. The results from FEM analysis indicate that a small tensile stress, which occurs on the dam surfaces with a maximum value of only $0.2 \mathrm{~Pa}$ near the dam base of the downstream surface, is observed, but the values are small when compared to the tensile strength of the dam concrete as shown in Table 3. More details about the thermal effects on the dam behavior can be found in the previous publication of the authors (Bui et al, 2019).

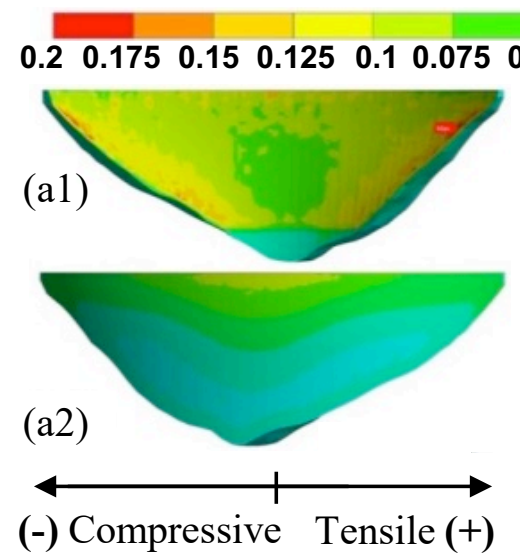

(a)

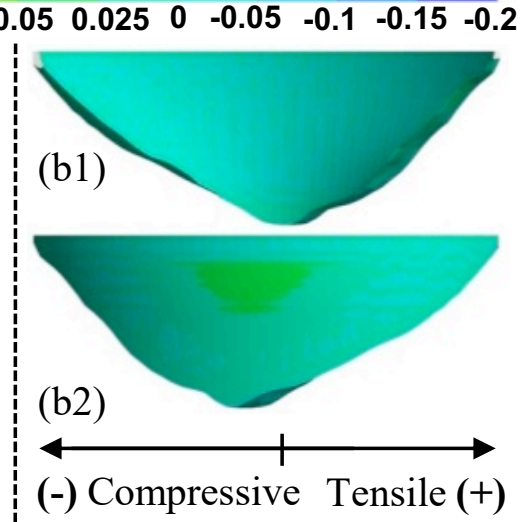

(b)

Figure 11. Maximum principal stress distribution ( $\mathrm{Pa}$ ) of the dam on (a) a day in winter: (a1) downstream face; (a2) upstream face, and (b) a day in summer: (b1) downstream face; (b2) upstream face. 


\section{Dam-Foundation Interaction}

An example of the absolute dam displacement relative to the foundation base at high and low reservoir water levels is shown in Figure 12. Due to a very small displacement when compared to the dam size, a scale of 1000 times is set to clarify the dam displacement at each dam elevation. It is noted that the parameters of the dam concrete and foundation rock are taken from case 1 (as shown in Table 3), while the water levels of $260.0 \mathrm{~m}$ and $220 \mathrm{~m}$ amsl are considered in the analysis. It can be seen that, at high water level, the center part of the dam moves downward to downstream, especially at the dam crest, while the left and right abutments move slightly upward to upstream.

(a)

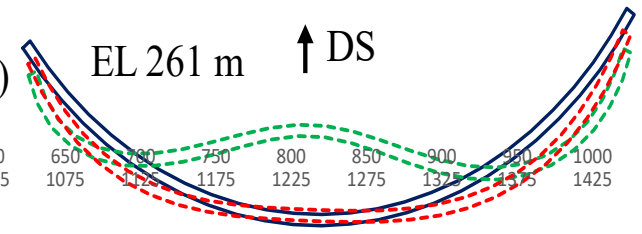

(b)

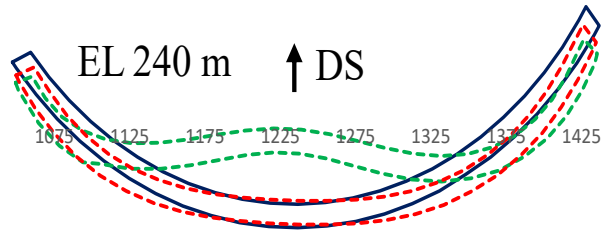

(c)

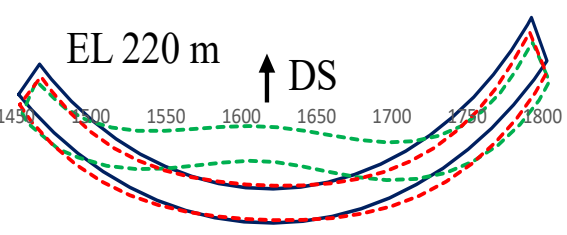

(d)

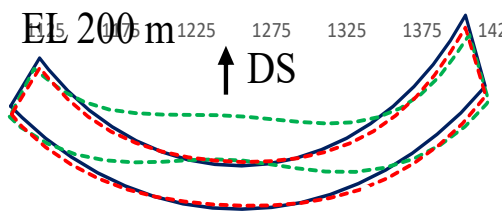

- No load

----· with loads, at WL. $260 \mathrm{~m}$ ----• with loads, at WL.220 m

- No load

----- with loads, at WL. $260 \mathrm{~m}$ ----. with loads, at WL.220 m

- No load

----. with loads, at WL. $260 \mathrm{~m}$ ----. with loads, at WL.220 m
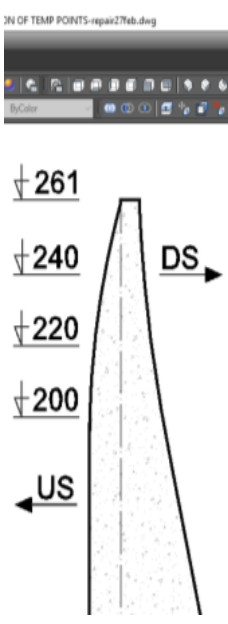

(e)

Figure 12. Example of displacements of the dam corresponding to WL $260 \mathrm{~m}$ and $220 \mathrm{~m}$ amsl at elevations: (a) $261 \mathrm{~m}$; (b) $240 \mathrm{~m}$; (c) $220 \mathrm{~m}$, and (d) $200 \mathrm{~m}$; (e) view of section.

\section{Effects of Deformation Modulus of Foundation on Deflection of the Dam}

Figure 13 shows the absolute radial deflection at the dam crest at high and low water levels. 


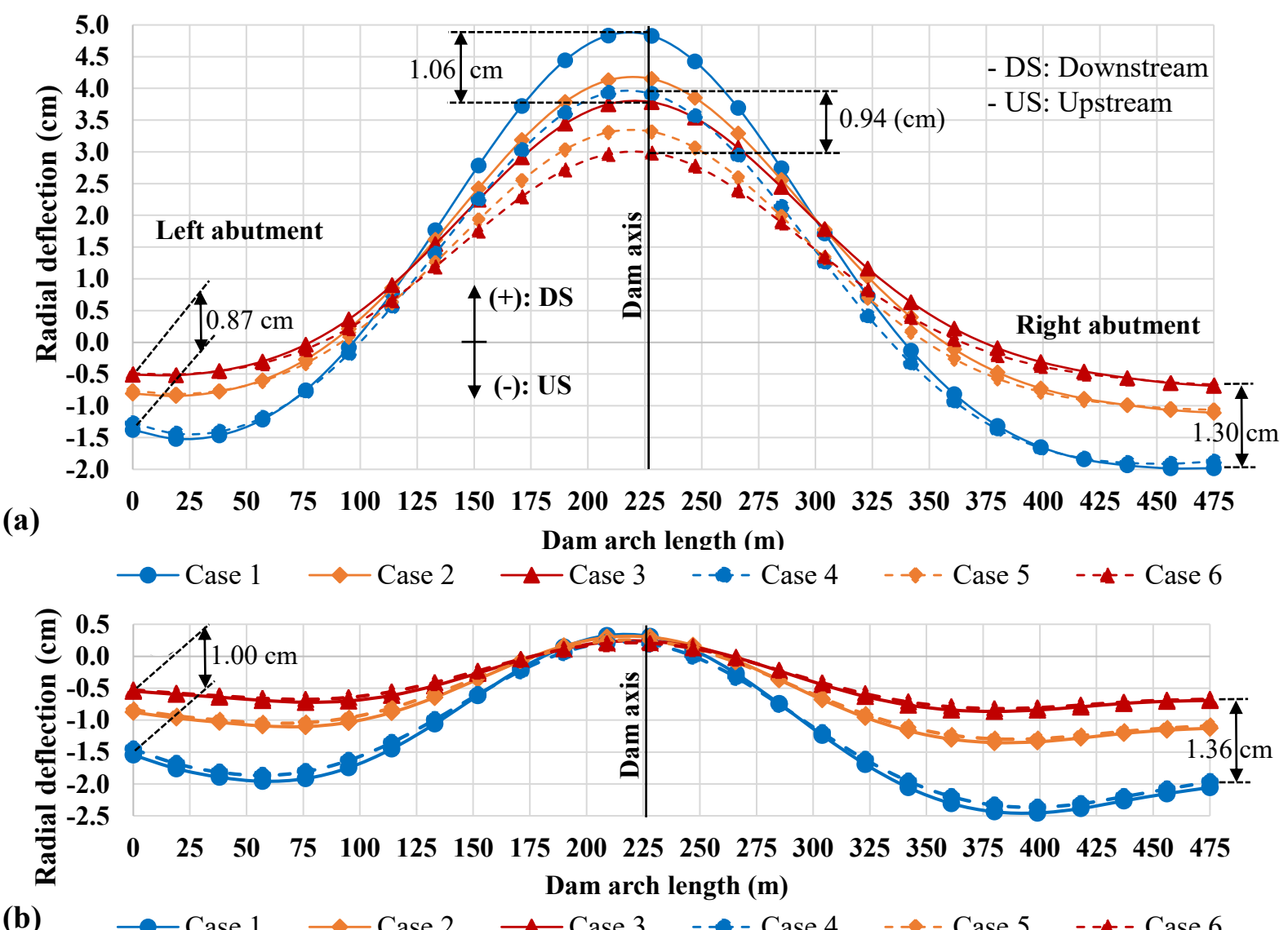

Figure 13. Absolute radial deflection at dam crest at (a) WL $260 \mathrm{~m}$ and (b) WL $220 \mathrm{~m}$ amsl.

In case of high water level (Figure 13a), when a low modulus of elasticity of concrete is kept at $33.3 \mathrm{GPa}$, increasing deformation modulus of foundation from $10 \mathrm{GPa}$ to $34.5 \mathrm{GPa}$ (cases 1-3) causes a reduction in radial deflection of $1.06 \mathrm{~cm}$ to downstream at the crest of crown section. Simultaneously, the reductions at the left and right abutments of $0.87 \mathrm{~cm}$ and $1.30 \mathrm{~cm}$ toward upstream, respectively, can be recorded. When a high modulus of elasticity of $44.2 \mathrm{GPa}$ is considered, the difference slightly reduces to $0.94 \mathrm{~cm}$ at the dam crest (cases 4-6). It means that the sensitivity of dam deflection to the change of modulus of foundation is reduced when the concrete modulus is increased.

In contrast, in case of low water level (Figure 13b), the modulus of foundation only affects the radial deflection of the dam near the abutments, while it has almost no effects at the crown section. As also can be seen, the modulus of foundation more dominantly affects the dam radial deflection (comparing case 1 with 3 and case 4 with 6 ), while the effects of modulus of concrete are not clearly seen (comparing case 1 with 4, case 2 with 5, and case 3 with 6).

In addition, along the distance of 100 and $140 \mathrm{~m}$ of arch length at the crest from left and right abutment, respectively, the tendency of the deflection at the dam crest is backward to upstream. This indicates that the role of the modulus of foundation in making the backward deflection at the abutments is meaningful. The lower modulus of foundation can cause the higher backward deflection to upstream at the abutments, and vice versa. For more details, Figure 14 shows an example of the comparison of the radial deflection along the dam crest between rigid foundation 
and deformed foundation (case 5). If the foundation is a rigid foundation, the radial deflection of the dam along the arch at the crest mostly moves to downstream, and the radial deflection is zero at the abutments when the water level is high (260 $\mathrm{m}$ amsl), while it is almost zero and almost constant when the water level is low ( $220 \mathrm{~m}$ amsl). However, when the foundation is deformable (case 5 as the example), backward radial deflection near the abutments toward upstream can be observed for both high and low water levels. It means that when the modulus of the foundation is higher, the lower dam crest deflection at abutments can be recorded, and vice versa. As also can be seen, due to an asymmetry of the valley at the dam site, the deflections of the dam at left and right abutments are not the same.

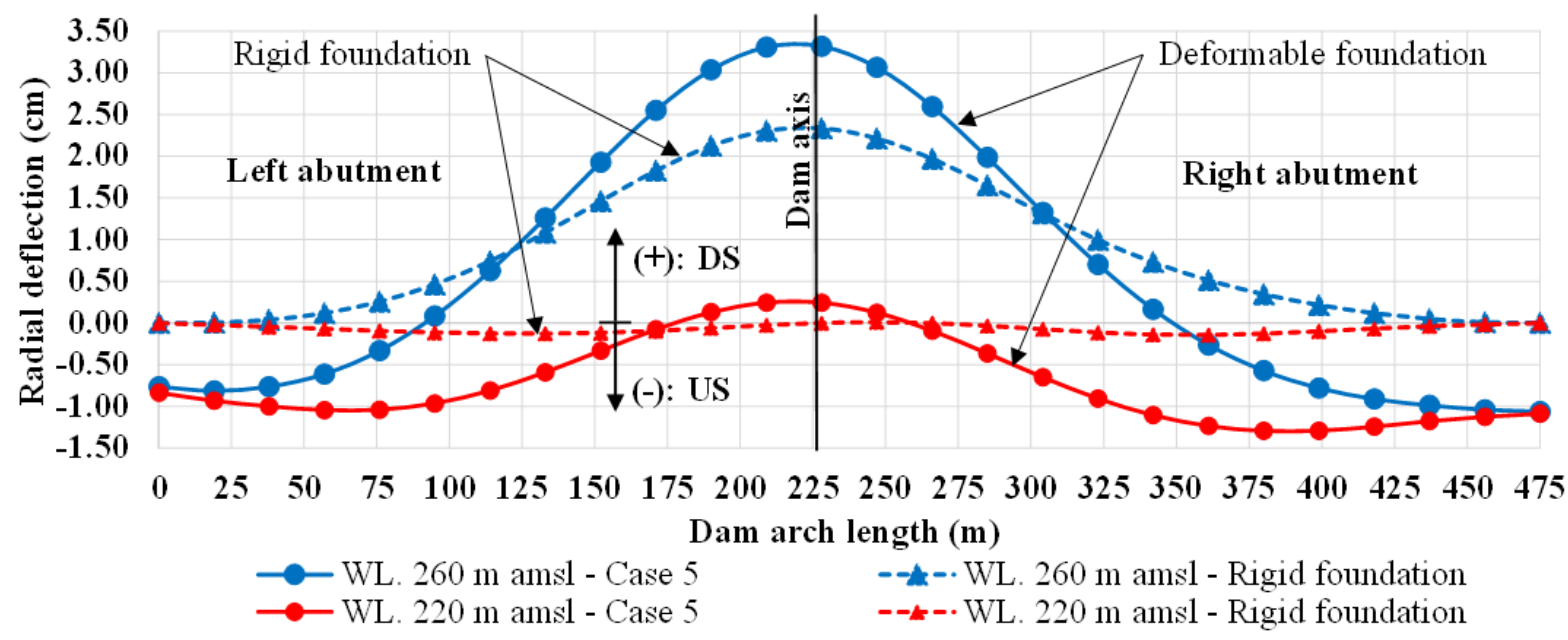

Figure 14. Absolute radial deflection at dam crest with a rigid foundation and deformable foundation at different water levels.

\section{Effects of Eelasticity Modulus of Concrete on Deflection of the Dam}

In case of high water level (Figure 13a), when considering the same values of foundation modulus of 10, 20, and $34.5 \mathrm{GPa}$, if the modulus of concrete increases from $33.3 \mathrm{GPa}$ to $44.2 \mathrm{GPa}$, the maximum radial deflection at the axis of the dam crest reduces from 4.83 to $3.93 \mathrm{~cm}$ (for cases 1 and 4), from 4.15 to $3.32 \mathrm{~cm}$ (for cases 2 and 5), and from 3.78 to $2.99 \mathrm{~cm}$ (for cases 3 and 6), corresponding to the reductions of $0.92,0.83$, and $0.80 \mathrm{~cm}$, respectively. This indicates that the dam deflection at the dam crest of the crown section is reduced when the modulus of concrete is increased, and vice versa.

However, when the water level is low (Figure 13b), the modulus of concrete does not affect much the radial deflection at the axis of dam crest. In addition, the modulus of concrete has small effects on the radial deflection at the abutments (comparing case 1 with 4 , case 2 with 5, and case 3 with 6).

\section{Effects of Modulus of Concrete and Foundation on Stresses of Dam}

The normal stresses of concrete in the radial and arch directions of the crown section in case of high water level (260.0 m amsl) are shown in Figure 15. 

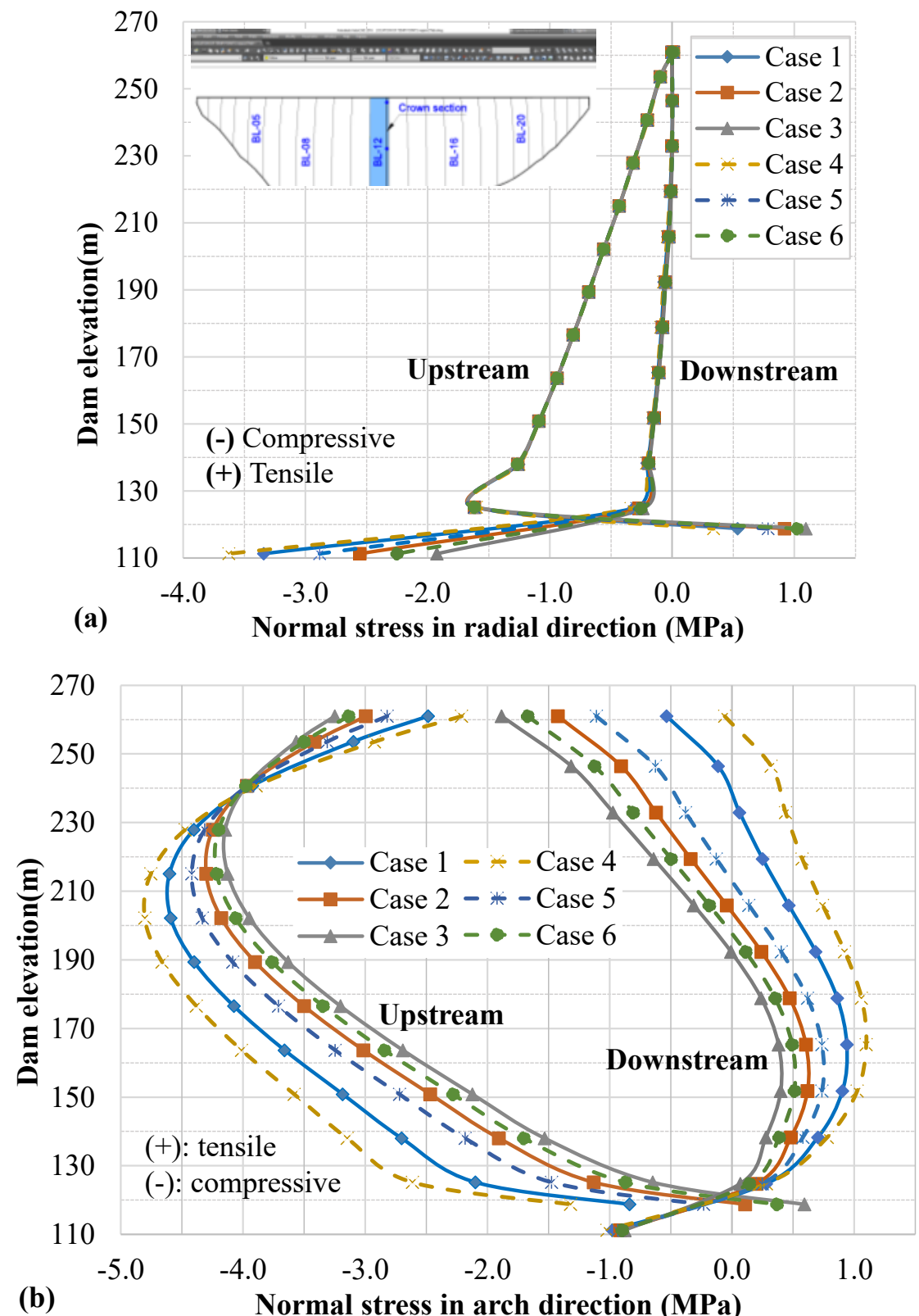

Figure 15. Normal stress of the crown section at WL $260 \mathrm{~m}$ amsl in (a) radial and (b) arch direction.

As can be seen in Figure 15a, in all analysis cases, the compressive normal stress mostly occurs in the entire crown section and is almost not affected by moduli of foundation and concrete. The concrete and foundation moduli mostly cause the difference of stress only near the dam-rock contact at upstream and downstream faces (elevation 111.3-120.0 $\mathrm{m}$ amsl in the downstream and elevation $118.8 \mathrm{~m}$ amsl in upstream). A minor tensile stress occurring at the upstream of the crown section near the dam base in all combined cases of concrete and foundation modulus can also be seen. 
In contrast, arch stress is affected significantly when considering the variation of moduli of concrete and foundation (Figure 15b). At the upstream side of the crown, only compressive stress is obtained at almost all crown elevations, except for cases 2, 3, and 6, which show a minor tensile stress at the base. The increase of foundation modulus reduces the compressive stress (cases 1, 2, and 3) in the crown elevations lower than $240 \mathrm{~m}$ amsl but, in contrast, increases the compressive stress at the elevations higher than $240 \mathrm{~m}$ amsl. At the crown of downstream, a lower foundation modulus (cases 1 and 4) causes tensile zone at almost all elevations. The increase of modulus of concrete and foundation reduces the magnitude of tensile stress along the height of the downstream face.

\section{Effects of Water Level}

Figure 16 shows the absolute radial deflection compared to the foundation base of the crown section. As can be seen, high water level (Figure 16a) induces larger dam radial deflections when compared to low water level (Figure 16b). Considering Figures 13a-b, it is indicated that the water level mainly affects the radial deflection at the middle part of the dam, especially at the crest of the crown section. When the water level reduces from $260 \mathrm{~m}$ to $220 \mathrm{~m}$ amsl, the difference of radial deflection at this location reduces from $4.52 \mathrm{~cm}$ to $2.78 \mathrm{~cm}$ if both the concrete and foundation moduli are increased from their minimum (case 1) to their maximum (case 6), respectively.

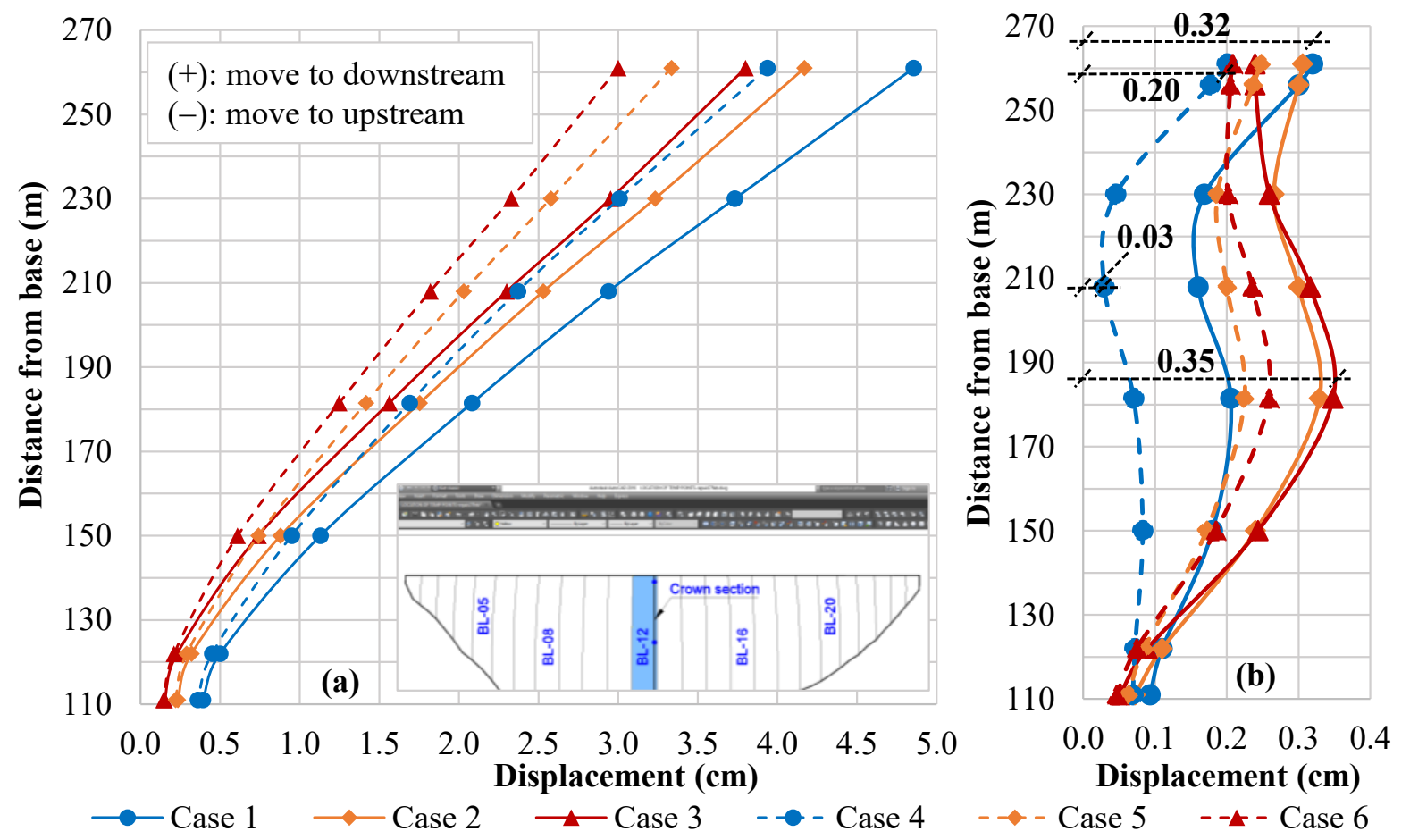

Figure 16. Absolute radial deflection the dam at the crown section at corresponding to (a) WL $260 \mathrm{~m}$ and (b) WL 220m amsl.

On the contrary, the dam deflection at abutments only slightly changes, i.e., $0.87 \mathrm{~cm}$ and $1.00 \mathrm{~cm}$ at left abutment as well as $1.30 \mathrm{~cm}$ and $1.36 \mathrm{~cm}$ at the right abutment corresponding to the water levels of $260.0 \mathrm{~m}$ amsl and $220 \mathrm{~m}$ amsl, respectively (see Figure 13). 
When the foundation modulus is increased from 10 to $34.3 \mathrm{GPa}$, the dam deflection at the crest decreases from 3.93 to $3.00 \mathrm{~cm}$ and from 4.85 to $3.79 \mathrm{~cm}$ corresponding to the low $(33.3 \mathrm{GPa})$ and high $(44.2 \mathrm{GPa})$ concrete modulus, respectively. It is because higher modulus of foundation can resist higher load, resulting in a reduction of the dam deflection.

In contrast, the dam deflection at low water level $(220 \mathrm{~m}$ amsl) is quite small. The deflections around the midheight at the elevations from $170 \mathrm{~m}$ to $210 \mathrm{~m}$ amsl are more sensitive to material properties $(0.03-0.35 \mathrm{~cm})$ than those at the dam crest $(0.2-0.32 \mathrm{~cm})$.

Figure 17 shows the absolute radial deflection compared to the foundation base of the section near the right abutment (block 16).

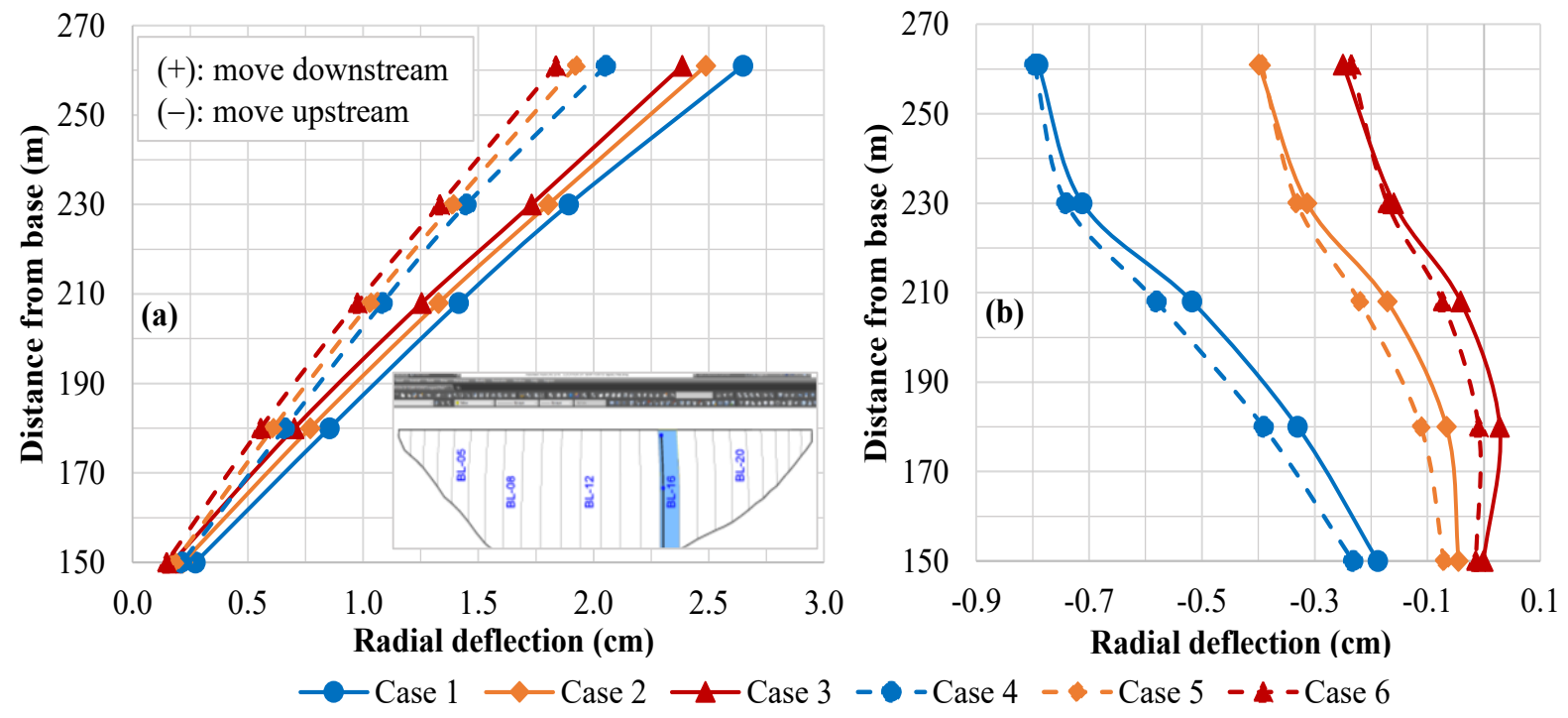

Figure 17. Absolute radial deflection of the dam at near right abutment (block 16) corresponding to (a) WL $260 \mathrm{~m}$ and (b) WL 220m amsl.

It can be seen that, due to the lower height and thicker section than that at the crown section, the radial deflection at the crest at the abutment (Figure 17a) is smaller than that at the crown section (Figure 16a) when the water level is high. In addition, the abutments move backward to the upstream when the water level reduces from high water level $(260 \mathrm{~m}$ amsl) to low water level $(220 \mathrm{~m}$ amsl$)$ as can be seen in Figure $17 \mathrm{~b}$. The radial deflection at the dam abutments is more sensitive to the modulus of foundation than to the modulus of concrete.

\section{Comparison of Analysis Results and Monitored Data}

The FE analysis results are compared with the actual structural behavior of dam measured by plumb line. Figure 18 shows the location of points measured by plumb line equipment at blocks 8, 12, and 16. Data observed from plumb lines located in blocks 12 and 16 are used to compare with the deflections from the analysis. The average values of the two plumb lines for each reservoir water level (during a recorded period of reservoir water operation from 20002015) are used to compare and evaluate the accuracy of different analysis cases with the aim to find out the suitable moduli of concrete and foundation of current old arch dam. It is noted that the values of dam deflection measured by plumb lines for different water levels are the values relative to the lowest water level in this period (215.4 $\mathrm{m}$ amsl), 
and the dam deflection is initialized at the lowest station of the plumb line equipment (El.122 $\mathrm{m}$ amsl) of the crown section for measuring deflection at different dam elevations.

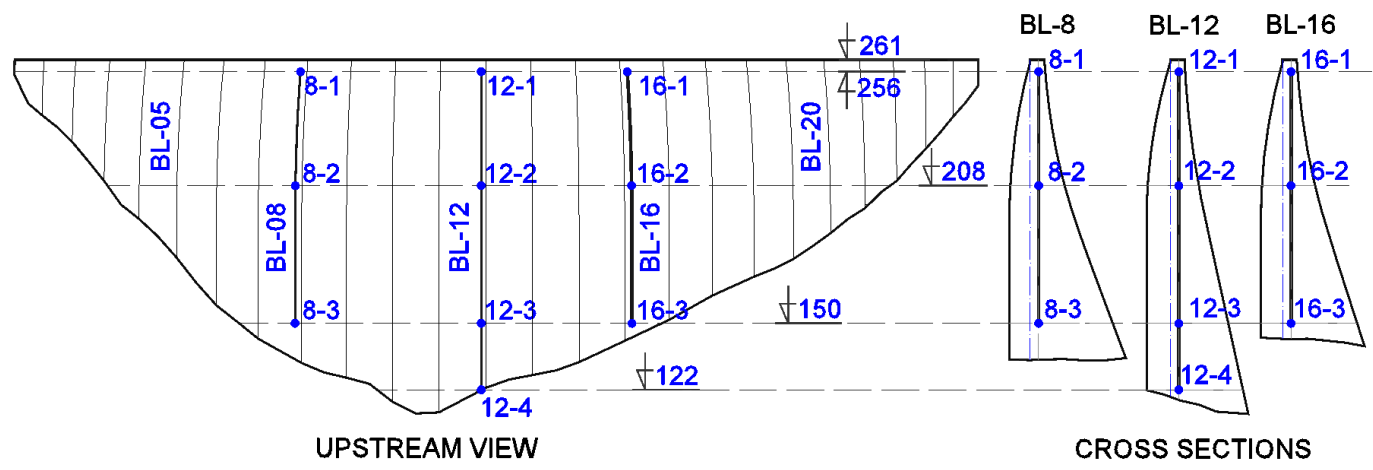

Figure 18. Location of observed points by plumb line at blocks 8, 12, and 16 .

Figure19 shows the relationships between dam deflection in radial direction and distance from the dam base at the high water level (260 m amsl) measured at blocks 12 and 16, respectively.
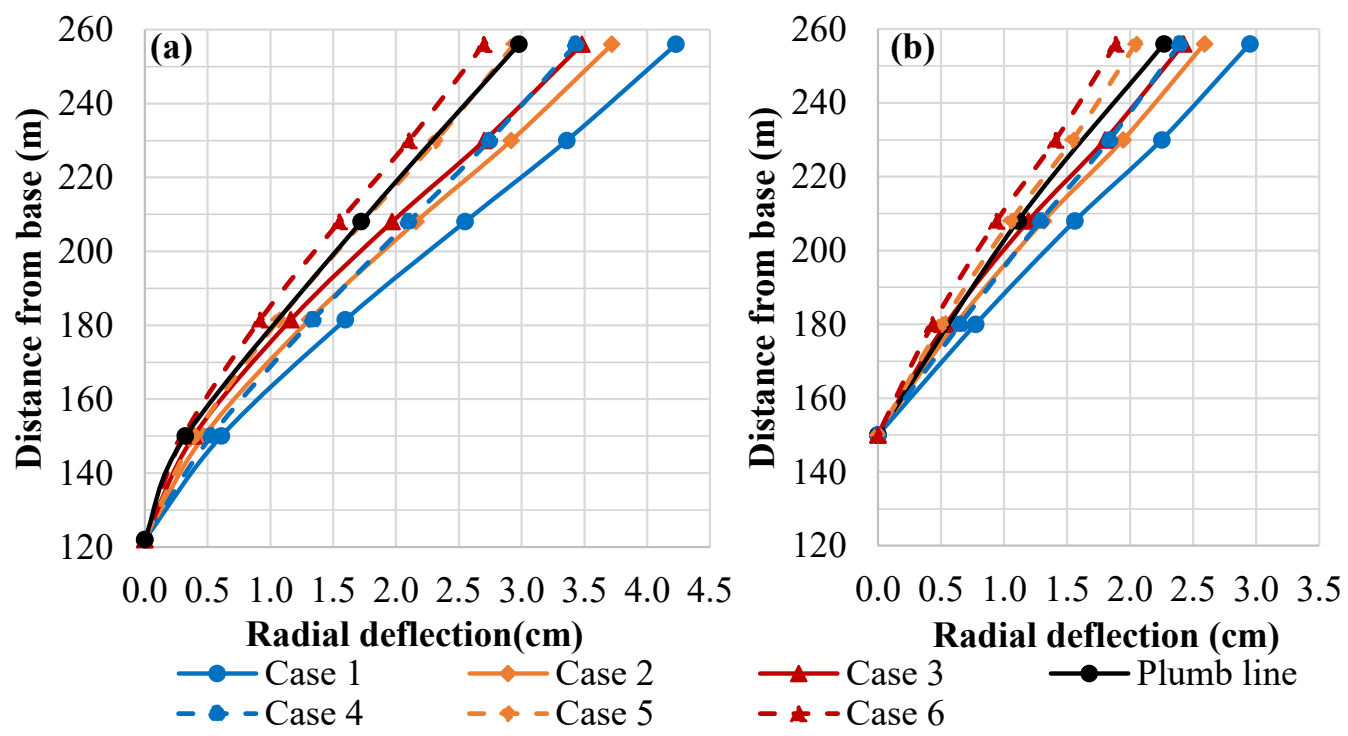

Figure 19. Relative radial deflection of the dam at WL $260 \mathrm{~m}$ amsl at (a) block 12 and (b) block 16.

The analysis results indicate that the analyzed radial deflections of the dam in case 5 with the modulus of concrete of $44.2 \mathrm{GPa}$ and deformation modulus of the foundation of $20 \mathrm{GPa}$ give the best fit with the measured data from the plumb lines. Both Root Mean Square Error (RMSE) and maximum error are only $0.04 \mathrm{~cm}$ at block 12 at a high WL (260 m amsl). Cases 3 and 4 at block 16 (at WL $260 \mathrm{~m}$ amsl) give smaller errors than case 5, but the differences are very small, as shown in Table 5. Moreover, the deflection curves of case 5 best fit the measured data. It can be seen that the modulus of concrete of $44.2 \mathrm{GPa}$ is reasonable because it is the value obtained from the test of cored samples taken in 2010, which is not the early age data. In addition, the selected deformation modulus of the foundation of $20 \mathrm{GPa}$ is also rational as it falls in the range of rock mass classification by GSI (see Table 1). 
Table 5. Root Mean Square Error (RMSE) and Maximum Error (ME) of analysis cases at high and low water levels.

\begin{tabular}{|c|c|c|c|c|c|c|}
\hline Case & 1 & 2 & 3 & 4 & 5 & 6 \\
\hline \multicolumn{7}{|c|}{ At WL $260 \mathrm{~m}$ amsl } \\
\hline Block 12 & $\begin{array}{c}0.76 \\
(1.25) \\
\end{array}$ & $\begin{array}{c}0.44 \\
(0.74) \\
\end{array}$ & $\begin{array}{c}0.28 \\
(0.50) \\
\end{array}$ & $\begin{array}{c}0.31 \\
(0.45) \\
\end{array}$ & $\begin{array}{c}0.04 \\
(-0.04) \\
\end{array}$ & $\begin{array}{c}0.16 \\
(-0.28) \\
\end{array}$ \\
\hline Block 16 & $\begin{array}{c}0.47 \\
(0.68) \\
\end{array}$ & $\begin{array}{c}0.22 \\
(0.32) \\
\end{array}$ & $\begin{array}{c}0.10 \\
(0.16) \\
\end{array}$ & $\begin{array}{c}0.13 \\
(0.12) \\
\end{array}$ & $\begin{array}{c}0.13 \\
(0.18) \\
\end{array}$ & $\begin{array}{c}0.24 \\
(-0.22) \\
\end{array}$ \\
\hline Total & $\begin{array}{c}1.23 \\
(1.93) \\
\end{array}$ & $\begin{array}{c}0.66 \\
(1.06) \\
\end{array}$ & $\begin{array}{c}0.38 \\
(0.66) \\
\end{array}$ & $\begin{array}{c}0.43 \\
(0.57) \\
\end{array}$ & $\begin{array}{c}0.17 \\
(0.22) \\
\end{array}$ & $\begin{array}{c}0.40 \\
(0.50)\end{array}$ \\
\hline \multicolumn{7}{|c|}{ At WL $220 \mathrm{~m}$ amsl } \\
\hline Block 12 & $\begin{array}{c}0.08 \\
(0.14) \\
\end{array}$ & $\begin{array}{c}0.06 \\
(0.11) \\
\end{array}$ & $\begin{array}{c}0.06 \\
(0.10) \\
\end{array}$ & $\begin{array}{c}0.06 \\
(0.11) \\
\end{array}$ & $\begin{array}{c}0.04 \\
(0.08) \\
\end{array}$ & $\begin{array}{c}0.03 \\
(0.06) \\
\end{array}$ \\
\hline Block 16 & $\begin{array}{c}0.09 \\
(0.15) \\
\end{array}$ & $\begin{array}{c}0.08 \\
(0.13) \\
\end{array}$ & $\begin{array}{c}0.07 \\
(0.12) \\
\end{array}$ & $\begin{array}{c}0.08 \\
(0.12) \\
\end{array}$ & $\begin{array}{c}0.06 \\
(0.10)\end{array}$ & $\begin{array}{c}0.06 \\
(0.10) \\
\end{array}$ \\
\hline Total & $\begin{array}{c}0.17 \\
(0.29)\end{array}$ & $\begin{array}{c}0.14 \\
(0.24)\end{array}$ & $\begin{array}{c}0.13 \\
(0.22)\end{array}$ & $\begin{array}{c}0.14 \\
(0.20)\end{array}$ & $\begin{array}{c}0.10 \\
(0.18)\end{array}$ & $\begin{array}{c}0.09 \\
(0.16)\end{array}$ \\
\hline
\end{tabular}

When the water level is low $(220 \mathrm{~m}$ amsl), all results of the radial deflection from analysis cases seem to overestimate the actual monitored data, but the maximum differences are very small (only in a range of 0.06-0.14 $\mathrm{cm}$ at block 12, and $0.10-0.15 \mathrm{~cm}$ at block 16, respectively, as shown in Figures 20a-b, respectively). It is noted here that the precision of the plumb line with human reading is $\pm 0.05 \mathrm{~cm}$ (Ribeiro et al., 2008).
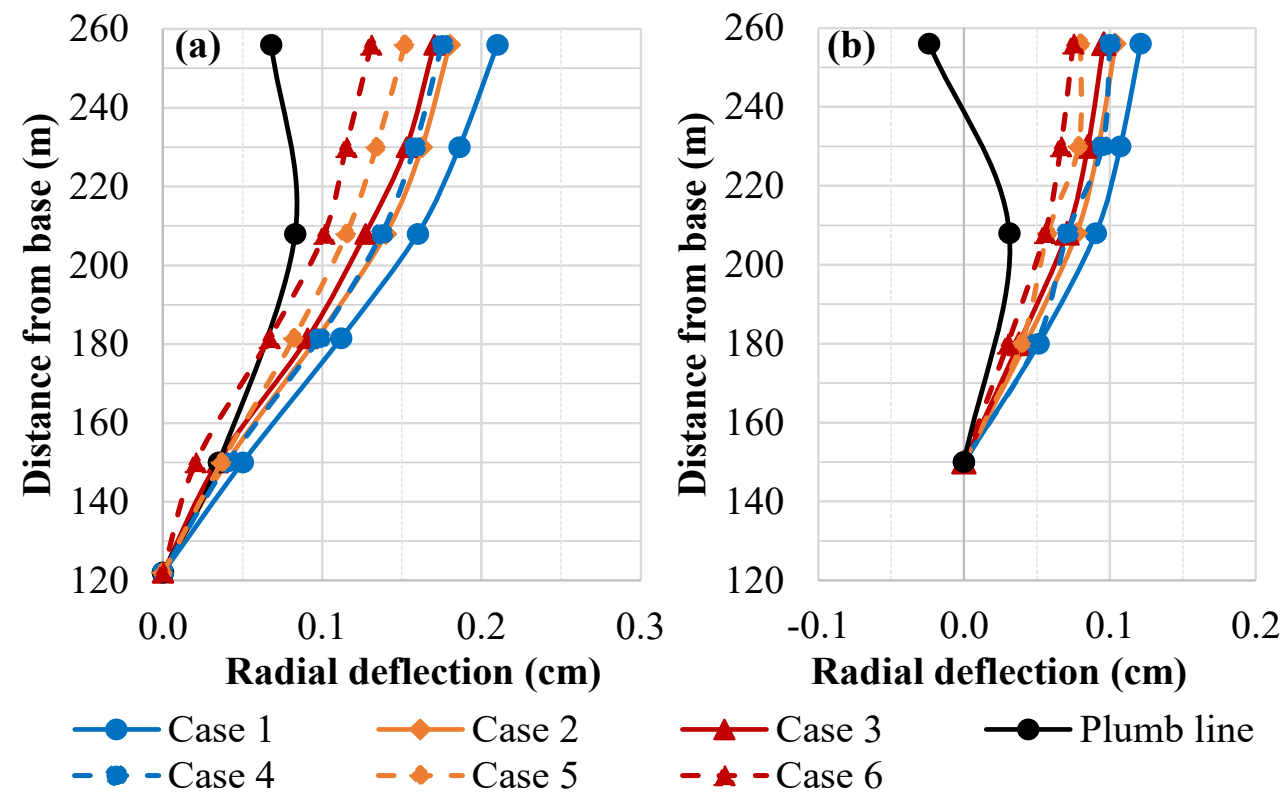

Figure 20. Relative radial deflection of the dam at WL $220 \mathrm{~m}$ amsl at (a) block 12 and (b) block 16. 
Based on the most suitable material properties, the safety of the dam is evaluated. Figure 21 shows the safety factor (SF), evaluated based on principal stress, on the dam faces of case 5. Almost all parts on the dam faces are in compression and satisfy the stress safety requirement. Only a minor tensile stress occurring near the dam base is recorded from the model. Almost all parts of the dam possess SF over 2.0 with only a very small part near the damrock surface at the upstream showing SF between 1 and 2. The size of the zone showing tension or low SF in the thickness direction is estimated to be negligible (only in the node at the dam-rock interface) compared to the thickness at the dam base, as can be seen from the section 1-1 together with its blow-up figure (Zone A) in Figure 21. So, it implies that the dam has high SF when considering static load case. This agrees well with the inspection results of the dam surfaces of which cracking was not found even in the vicinity near the dam-rock interface.

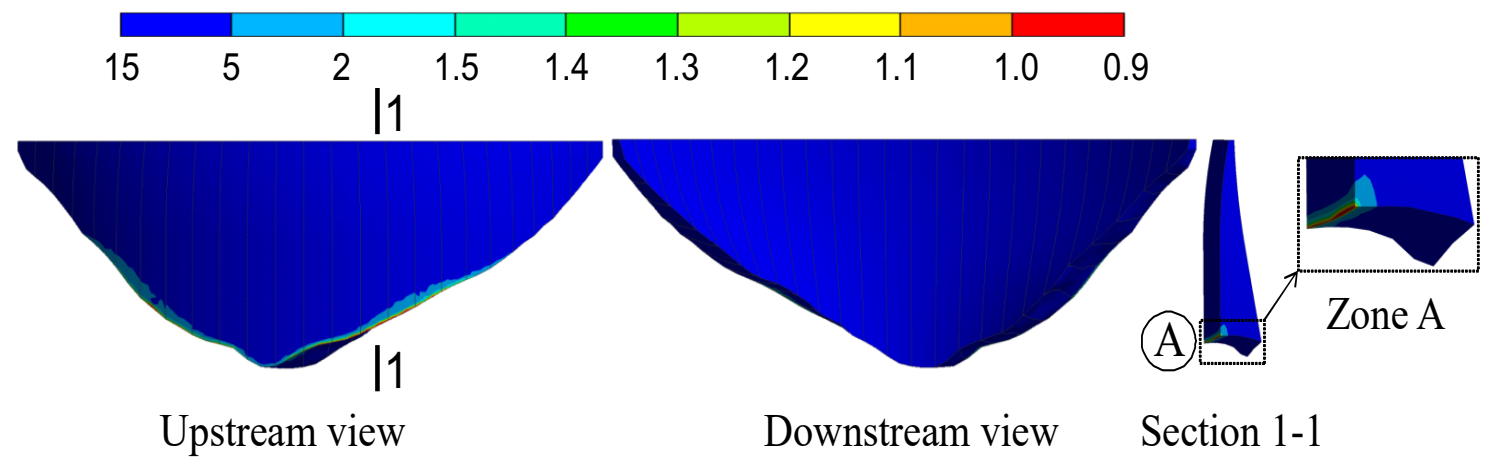

Figure 21. A safety factor of stress on the dam faces at WL $260 \mathrm{~m}$ amsl.

\section{CONCLUSIONS}

According to the FEM analysis results and the comparison with the monitored data, the following conclusions can be obtained:

1. Uncertainties of material properties are a crucial role affecting the dam structural behavior. Most of the material properties change with time from the designed value.

- Modulus of elasticity of concrete increased significantly at the long term. As a result, deflection of the existing old dam reduced significantly.

- Deformation modulus of the foundation rock is difficult to measure at site. Estimation based on classification index is used. The most suitable value is significantly lower than the designed value.

2. Due to the effects of deformation modulus of foundation, the abutments deformed more to upstream in case of low deformation modulus. The asymmetry of the dam shape and the variation of the dam thickness along the arch at different elevations also cause the unequal deflections of the abutments at the left and right sides. Monitoring of abutment movement should be conducted in the future.

3. Variation of seasonal air temperature and solar radiation does not affect significantly the deflection and stress of the dam.

4. By considering aging effect of material, the safety of the dam is evaluated. Analysis results are confirmed by plumb line monitoring. Most of the dam body is in compression, except a minor tensile stress occurring along the dam base in the upstream face. However, it does not affect the dam safety.

5. At current state, the concrete and foundation moduli, which are $44.2 \mathrm{GPa}$ and $20 \mathrm{GPa}$, respectively, give the best results compared to the monitored data measured by plumb line. 


\section{ACKNOWLEDGMENT}

The authors would like to acknowledge the Electricity Generating Authority of Thailand, Center of Excellence in Material Science, Construction and Maintenance Technology Project, Thammasat University, and the Chair Professor Grant (P-19-52302), the National Science and Technology Development Agency (NSTDA), Thailand for supporting this study.

\section{REFERENCES}

ACI 318-19. 2019. Building code requirements for structural concrete and commentary. American Concrete Institute, USA.

Altunisik A.C., Kalkan E. \& Basaga H.B. 2018. Development of engineering software to predict the structural behavior of arch dams. Advances in Computational Design, 3(1): 87-112.

ANSYS, 2017. ANSYS Inc., Release 18.2.

Bui A.K., Sancharoen P., Tanapornraweekit G., Tangtermsirikul, S. \& Nanakorn, P. 2019. An evaluation of thermal effects on behavior of a concrete arch dam. Songklanakarin Journal of Science and Technology, 41(5): 1059-1068.

Bureau of Reclamation 1963. Concrete and structural report: Concrete mix investigation - Bhumibol dam Yanhee project, Thailand. Department of the Interior, United States.

Bureau of Reclamation 1955. Engineering geology (Appendix ii) - Yanhee dam site, Thailand. Department of the Interior, United States.

Campos A., Lopez C.M., Blanco A. \& Aguado, A. 2018. Effects of an internal sulfate attack and an alkaliaggregate reaction in a concrete dam. Construction and Building Materials, 166: 668-683.

Chopra A.K. \& Wang J.T. 2010. Earthquake response of arch dams to spatially varying ground motion. Earthquake Engineering and Structural Dynamics, 39(8): 887-906.

Colombo M., Domaneschi M. \& Ghisi A. 2016. Existing concrete dams: Loads definition and finite element models validation. Structural Monitoring \& Maintenance, 3: 129-144.

Fenves G.L., Mojtahedi S. \& Reimer R.B. 1992. Effect of contraction joints on earthquake response of an arch dam. Journal of Structural Engineering, 118(4): 1039-1055.

FERC. 1999. Engineering guidelines for the evaluation of hydropower projects: Chapter 11-Arch dams. Division of Dam Safety and Inspections, Federal Energy Regulatory Commission, Washington, D.C.

Ferdousi A., Gharabaghi A.R.M., Ahmadi M.T., Chenaghlou, M. \& Tabrizi, M.E. 2014. Earthquake analysis of arch dams including the effects of foundation discontinuities and proper boundary conditions. Journal of Theoretical and Applied Mechanics, 52(3): 579-594.

Fok K.I. \& Chopra A.K., 1987. Water compressibility in earthquake response of arch dams. Journal of Structural Engineering, 113(5): 958-975.

Ghaemian M. \& Sohrabi-Gilani M. 2012. Seismic responses of arch dams due to non-uniform ground motions. Scientia Iranica, 19(6): 1431-1436.

Hariri-Ardebili M.A. \& Kianoush M.R. 2014. Integrative seismic safety evaluation of a high concrete arch dam. Soil Dynamics and Earthquake Engineering, 67: 85-101.

Hariri-Ardebili M.A. \& Kianoush M.R. 2015. Seismic analysis of a coupled dam-reservoir-foundation system considering pressure effects at opened joints. Structure and Infrastructure Engineering, 11(7): 833-850.

Hariri-Ardebili M.A., Mirzabozorg H. \& Ghaemian M. 2013. Pulvino and peripheral joint effects on static and seismic safety of concrete arch dams. Scientia Iranica. Transaction A, Civil Engineering, 20(6): 1579-1594.

Hoek E. \& Brown E.T. 1997. Practical estimates of rock mass strength. International Journal of Rock Mechanics and Mining Sciences, 34(8): 1165-1186.

Hoek E. \& Diederichs M.S. 2006. Empirical estimation of rock mass modulus. International Journal of Rock Mechanics and Mining Sciences, 43(2): 203-215. 
Holman J. 2010. Heat transfer. New York: Mc-Graw-Hill Companies Inc.

Jin F., Chen Z., Wang J., Yang, J. 2010. Practical procedure for predicting non-uniform temperature on the exposed face of arch dams. Applied Thermal Engineering, 30(14): 2146-2156.

Karabulut M. \& Genis M. 2019. Pseudo seismic and static stability analysis of the Torul dam. Geomechanics and Engineering, 17(2): 207-214.

Khaneghahi M.H., Alembagheri M. \& Soltani N. 2019. Reliability and variance-based sensitivity analysis of arch dams during construction and reservoir impoundment. Frontiers of Structural and Civil Engineering, 13(3): 526-541.

Leger P., Venturelli J. \& Bhattacharjee S. 1993. Seasonal temperature and stress distributions in concrete gravity dams. Part 2: Behaviour. Canadian Journal of Civil Engineering, 20(6): 1018-1029.

Lin G., Du J. \& Hu Z. 2007. Earthquake analysis of arch and gravity dams including the effects of foundation inhomogeneity. Frontiers of Architecture and Civil Engineering in China, 1(1): 41-50.

Matsuo T., Nishiuchi T., Kanazu T. \& Ueda, M. 1999. Investigation on the static behavior of an aged arch dam based on in-situ test results. Journal of Japan Society of Dam Engineers, 9(1): 4-12.

Mirzabozorg H., Akbari M. \& Hariri-Ardebili M. 2013. Nonlinear seismic response of a concrete arch dam to spatially varying earthquake ground motions. Asian Journal of Civil Engineering (BHRC), 14(6): 859-879.

Mirzabozorg H., Hariri-Ardebili M.A., Shirkhan M. \& Seyed-Kolbadi, S.M. 2014. Mathematical modeling and numerical analysis of thermal distribution in arch dams considering solar radiation effect. The Scientific World Journal, 2014: 1-15.

Nishiuchi T. \& Sakata K. 2006. Investigation on static behavior of existing arch dams using finite element method considering nonlinear behavior of transverse joints (in japanese). Journal of Japan Society of Civil Engineering E, 62(4): 672-688.

Perner F. \& Obernhuber P. 2010. Analysis of arch dam deformations. Frontiers of Architecture and Civil Engineering in China, 4(1): 102-108.

Pourbehi M.S. \& van Zijl G.P. 2019. Seismic analysis of the Kleinplaas dam affected by alkali-silica reaction using a chemo-thermo-mechanical finite element numerical model considering fluid structure interaction. Journal of Advanced Concrete Technology, 17(8): 462-473.

Raphael, J.M. 1984. Tensile strength of concrete. Journal Proceedings, 81(2):158-165.

Raychowdhury P. \& Jindal S. 2014. Shallow foundation response variability due to soil and model parameter uncertainty. Frontiers of Structural and Civil Engineering, 8(3): 237-251.

Ribeiro F.C.D., Fazan J.A., Netto N.P., Blitzkow, D., da Fonseca Junior, E.S., Cintra, J.P., Fiorini, A.S. \& Neves, C.P. 2008. Comparison between geodetic technology and plumb lines in monitoring of displacements on Itapu dam. 13th FIG Symbosium on Deformation Measurement and Analysis, Lisbon, Portugal.

Royal Irrigation Department 1963. Final construction report - Yanhee multipurpose project. Ministry of National Development, Thailand.

Santillán D., Salete E., Vicente D. \& Toledo, M.Á. 2014. Treatment of solar radiation by spatial and temporal discretization for modeling the thermal response of arch dams. Journal of Engineering Mechanics, 140(11): 01-18.

Sheibany F. \& Ghaemian M. 2006. Effects of environmental action on thermal stress analysis of karaj concrete arch dam. Journal of Engineering Mechanics, 132(5): 532-544.

Tan H. \& Chopra A.K. 1995. Earthquake analysis of arch dams including dam-water-foundation rock interaction. Earthquake Engineering and Structural Dynamics, 24(11): 1453-1474.

USACE. 1994. Engineering and design - Arch dam design. Department of the Army, US Army Corps. of Engineers, Washington, D.C.

Varughese J.A. \& Nikithan S. 2016. Seismic behavior of concrete gravity dams. Advances in Computational Design, 1(2): 195-206.

Wang, J.T., Lv, D.D., Jin, F. \& Zhang, C.H. 2013. Earthquake damage analysis of arch dams considering damwater-foundation interaction. Soil Dynamics and Earthquake Engineering, 49: 64-74. 
Wang J.T. \& Chopra A.K. 2010. Linear analysis of concrete arch dams including dam-water-foundation rock interaction considering spatially varying ground motions. Earthquake Engineering and Structural Dynamics, 39(7): 731-750.

Wang J.T., Zhang C.H. \& Jin F. 2012. Nonlinear earthquake analysis of high arch dam-water-foundation rock systems. Earthquake Engineering and Structural Dynamics, 41(7): 1157-1176.

Wieland M. \& Kirchen G. 2012. Long-term dam safety monitoring of punt dal gall arch dam in switzerland. Frontiers of Structural and Civil Engineering, 6(1): 76-83.

Wu B., Niu J., Su H., Yang, M., Wu, Z. \& Cui, X. 2019. An approach for deformation modulus mechanism of super-high arch dams. Structural Engineering and Mechanics, 69(5): 557-566.

Zhang C., Xu Y., Wang G. \& Jin, F. 2000. Non-linear seismic response of arch dams with contraction joint opening and joint reinforcements. Earthquake Engineering and Structural Dynamics, 29(10): 1547-1566.

Zhang Q.L., Li D.Y., Hu C. \& Hu, L. 2019. Numerical investigation into underwater explosion-resistant performance of an arch dam considering its transverse contraction and control joints. Journal of Performance of Constructed Facilities, 33(6): 04019078.

Zhang Q.L., Li D.Y., Hu L. \& Hu, C. 2019. Viscous damping and contraction joint friction in underwater explosion resistant design of arch dams. Journal of Performance of Constructed Facilities, 33(3): 04019020.

Zhong H., Lin G. \& Li H. 2009. Numerical simulation of damage in high arch dam due to earthquake. Frontiers of Architecture and Civil Engineering in China, 3(3): 316-322.

Zhou, J., Lin, G., Zhu, T., Jefferson, A.D. \& Williams, F.W. 2000. Experimental investigations into seismic failure of high arch dams. Journal of Structural Engineering, 126(8): 926-935.

Zhu B. 1997. Prediction of water temperature in deep reservoirs. Dam Engineering, 8: 13-25. 